\title{
Marine organic matter in the remote environment of the Cape Verde islands - an introduction and overview to the MarParCloud campaign
}

\author{
Manuela van Pinxteren ${ }^{1}$, Khanneh Wadinga Fomba ${ }^{1}$, Nadja Triesch ${ }^{1}$, Christian Stolle $^{2,3}$, Oliver Wurl ${ }^{3}$, \\ Enno Bahlmann ${ }^{2,4}$, Xianda Gong ${ }^{1}$, Jens Voigtländer ${ }^{1}$, Heike Wex ${ }^{1}$, Tiera-Brandy Robinson ${ }^{3}$, Stefan Barthel ${ }^{1}$, \\ Sebastian Zeppenfeld ${ }^{1}$, Erik Hans Hoffmann ${ }^{1}$, Marie Roveretto ${ }^{5}$, Chunlin Li ${ }^{5}$, Benoit Grosselin ${ }^{6}$, Veronique Daële ${ }^{6}$, \\ Fabian Senf ${ }^{1}$, Dominik van Pinxteren ${ }^{1}$, Malena Manzi ${ }^{7}$, Nicolás Zabalegui ${ }^{7}$, Sanja Frka ${ }^{8}$, Blaženka Gašparović ${ }^{8}$, \\ Ryan Pereira ${ }^{9}$, Tao $\mathrm{Li}^{10}$, Liang Wen ${ }^{10}$, Jiarong $\mathrm{Li}^{11}$, Chao Zhu ${ }^{11}$, Hui Chen ${ }^{11}$, Jianmin Chen ${ }^{11}$, Björn Fiedler ${ }^{12}$, \\ Wolf von Tümpling ${ }^{13}$, Katie Alana Read ${ }^{14}$, Shalini Punjabi ${ }^{14,15}$, Alastair Charles Lewis ${ }^{14,15}$, James Roland Hopkins ${ }^{14}$, \\ Lucy Jane Carpenter ${ }^{15}$, Ilka Peeken ${ }^{16}$, Tim Rixen ${ }^{4}$, Detlef Schulz-Bull ${ }^{2}$, María Eugenia Monge ${ }^{7}$, \\ Abdelwahid Mellouki $^{6,10}$, Christian George ${ }^{5}$, Frank Stratmann ${ }^{1}$, and Hartmut Herrmann ${ }^{1,10}$ \\ ${ }^{1}$ Leibniz Institute for Tropospheric Research (TROPOS), 04318 Leipzig, Germany \\ ${ }^{2}$ Leibniz Institute for Baltic Sea Research Warnemuende, 18119 Rostock, Germany \\ ${ }^{3}$ Institute for Chemistry and Biology of the Marine Environment, Carl-von-Ossietzky University Oldenburg, \\ 26382 Wilhelmshaven, Germany \\ ${ }^{4}$ Leibniz Centre for Tropical Marine Research (ZMT), 28359 Bremen, Germany \\ ${ }^{5}$ Univ Lyon, Université Claude Bernard Lyon 1, CNRS, IRCELYON, 69626, Villeurbanne, France \\ ${ }^{6}$ Institut de Combustion, Aérothermique, Réactivité et Environnement, \\ Centre National de la Recherche Scientifique, Orléans, France \\ ${ }^{7}$ Centro de Investigaciones en Bionanociencias (CIBION), Consejo Nacional de Investigaciones Científicas y \\ Técnicas (CONICET), C1425FQD, Ciudad de Buenos Aires, Argentina \\ ${ }^{8}$ Division for Marine and Environmental Research, Ruđer Bošković Institute, 10000 Zagreb, Croatia \\ ${ }^{9}$ The Lyell Centre, Heriot-Watt University, EH14 4AP, Edinburgh, UK \\ ${ }^{10}$ School of Environmental Science and Engineering, Shandong University, Qingdao, 266237, China \\ ${ }^{11}$ Shanghai Key Laboratory of Atmospheric Particle Pollution and Prevention, Institute of Atmospheric Sciences, \\ Fudan University, Shanghai, 200433, China \\ ${ }^{12}$ GEOMAR Helmholtz Centre for Ocean Research, Kiel, Germany \\ ${ }^{13}$ Helmholtz Centre for Environmental Research - UFZ, 39114 Magdeburg, Germany \\ ${ }^{14}$ National Centre for Atmospheric Science (NCAS), University of York, Heslington, York, YO10 5DD, UK \\ ${ }^{15}$ Wolfson Atmospheric Chemistry Laboratories, Department of Chemistry, University of York, \\ Heslington, York, YO10 5DD, UK \\ ${ }^{16}$ Polar Biological Oceanography, Alfred Wegener Institute Helmholtz Centre for Polar and Marine Research, \\ Bremerhaven, Germany
}

Correspondence: Manuela van Pinxteren (manuela@tropos.de) and Hartmut Herrmann (herrmann@ tropos.de)

Received: 29 October 2019 - Discussion started: 9 December 2019

Revised: 15 April 2020 - Accepted: 21 April 2020 - Published: 12 June 2020

Published by Copernicus Publications on behalf of the European Geosciences Union. 
Abstract. The project MarParCloud (Marine biological production, organic aerosol Particles and marine Clouds: a process chain) aims to improve our understanding of the genesis, modification and impact of marine organic matter (OM) from its biological production, to its export to marine aerosol particles and, finally, to its ability to act as ice-nucleating particles (INPs) and cloud condensation nuclei (CCN). A field campaign at the Cape Verde Atmospheric Observatory (CVAO) in the tropics in September-October 2017 formed the core of this project that was jointly performed with the project MARSU (MARine atmospheric Science Unravelled). A suite of chemical, physical, biological and meteorological techniques was applied, and comprehensive measurements of bulk water, the sea surface microlayer (SML), cloud water and ambient aerosol particles collected at a ground-based and a mountain station took place.

Key variables comprised the chemical characterization of the atmospherically relevant OM components in the ocean and the atmosphere as well as measurements of INPs and $\mathrm{CCN}$. Moreover, bacterial cell counts, mercury species and trace gases were analyzed. To interpret the results, the measurements were accompanied by various auxiliary parameters such as air mass back-trajectory analysis, vertical atmospheric profile analysis, cloud observations and pigment measurements in seawater. Additional modeling studies supported the experimental analysis.

During the campaign, the CVAO exhibited marine air masses with low and partly moderate dust influences. The marine boundary layer was well mixed as indicated by an almost uniform particle number size distribution within the boundary layer. Lipid biomarkers were present in the aerosol particles in typical concentrations of marine background conditions. Accumulation- and coarse-mode particles served as $\mathrm{CCN}$ and were efficiently transferred to the cloud water. The ascent of ocean-derived compounds, such as sea salt and sugar-like compounds, to the cloud level, as derived from chemical analysis and atmospheric transfer modeling results, denotes an influence of marine emissions on cloud formation. Organic nitrogen compounds (free amino acids) were enriched by several orders of magnitude in submicron aerosol particles and in cloud water compared to seawater. However, INP measurements also indicated a significant contribution of other non-marine sources to the local INP concentration, as (biologically active) INPs were mainly present in supermicron aerosol particles that are not suggested to undergo strong enrichment during ocean-atmosphere transfer. In addition, the number of $\mathrm{CCN}$ at the supersaturation of $0.30 \%$ was about 2.5 times higher during dust periods compared to marine periods. Lipids, sugar-like compounds, UV-absorbing (UV: ultraviolet) humic-like substances and low-molecularweight neutral components were important organic compounds in the seawater, and highly surface-active lipids were enriched within the SML. The selective enrichment of specific organic compounds in the SML needs to be studied in further detail and implemented in an OM source function for emission modeling to better understand transfer patterns, the mechanisms of marine OM transformation in the atmosphere and the role of additional sources.

In summary, when looking at particulate mass, we see oceanic compounds transferred to the atmospheric aerosol and to the cloud level, while from a perspective of particle number concentrations, sea spray aerosol (i.e., primary marine aerosol) contributions to both $\mathrm{CCN}$ and INPs are rather limited.

\section{Introduction and motivation}

The ocean covers around $71 \%$ of the Earth's surface and acts as a source and sink for atmospheric gases and particles. However, the complex interactions between the marine boundary layer (MBL) and the ocean surface are still largely unexplored (Cochran et al., 2017; de Leeuw et al., 2011; Gantt and Meskhidze, 2013; Law et al., 2013). In particular, the role of marine organic matter $(\mathrm{OM})$ with its sources and contribution to marine aerosol particles is still elusive. This includes, for example, how this particle fraction might lead to a variety of effects such as impacting health through the generation of reactive oxygen species, OM composition increasing or decreasing the absorption of solar radiation and therefore radiative properties, and impacting marine ecosystems via atmospheric deposition (e.g., Abbatt et al., 2019; Brooks and Thornton, 2018; Burrows et al., 2013; Gantt and Meskhidze, 2013; Pagnone et al., 2019; Patel and Rastogi, 2020). Furthermore, knowledge of the properties of marine organic aerosol particles and their ability to act as cloud condensation nuclei (CCN) or ice-nucleating particles (INPs) is not fully understood. The fraction of marine $\mathrm{CCN}$ made up of sea spray aerosol is still debated and suggested to comprise about $30 \%$ on a global scale (excluding the high southern latitudes) (Quinn et al., 2017). Important pieces of information about marine $\mathrm{CCN}$ are still missing (e.g., Bertram et al., 2018). Ocean-derived INPs were proposed to play a dominating role in determining INP concentrations in near-surface air over remote areas such as the Southern Ocean; however, their source strength in other oceanic regions and knowledge about which physicochemical properties determine the INP efficiency are still largely unknown (Burrows et al., 2013; McCluskey et al., 2018a, b). In recent years, it was clearly demonstrated that marine aerosol particles contain a significant organic mass fraction derived from primary and secondary processes (Middlebrook et al., 1998; Prather et al., 2013; Putaud et al., 2000; van Pinxteren et al., 2015, 2017). Although it is known that the main OM groups show similarities to oceanic composition and comprise carbohydrates, proteins, lipids, and humic-like and refractory organic matter, a large fraction of $\mathrm{OM}$ in the marine environment is still unknown at a molecular level, thereby limiting our ability to 
constrain interlinked processes (e.g., Gantt and Meskhidze, 2013).

The formation of ocean-derived aerosol particles and their precursors is influenced by the uppermost layer of the ocean, the sea surface microlayer (SML), which forms due to different physicochemical properties of air and water (Engel et al., 2017; Wurl et al., 2017). Recent investigations suggest that the SML is stable up to wind speeds of $>10 \mathrm{~m} \mathrm{~s}^{-1}$; it is therefore existent at the global average wind speed of $6.6 \mathrm{~m} \mathrm{~s}^{-1}$ and is a fixed component influencing the ocean-atmosphere interaction on global scales (Wurl et al., 2011). The SML is involved in the generation of sea spray (or primary) particles, including their organic fraction by the transfer of OM to rising bubbles before they burst out to jet droplets and film droplets (de Leeuw et al., 2011). A mechanistic and predicable understanding of these complex and interacting processes is still lacking (e.g., Engel et al., 2017). Moreover, surface films influence air-sea gas exchange and may undergo (photo)chemical reactions, leading to the production of unsaturated and functionalized volatile organic compounds (VOCs) acting as precursors for the formation of secondary organic aerosol (SOA) particles (Brueggemann et al., 2018; Ciuraru et al., 2015). Thus, the dynamics of OM and especially the surface-active compounds present at the air-water interface may have global impacts on the air-sea exchange processes necessary to understand oceanic feedbacks on the atmosphere (e.g., Pereira et al., 2018).

Within the SML, OM is a mixture of different compounds including polysaccharides, amino acids, proteins, lipids and chromophoric dissolved organic matter (CDOM) that are either dissolved or particulate (e.g., Gašparović et al., 1998a, 2007; Stolle et al., 2019). In addition, the complex microbial community is assumed to exert a strong control on the concentration and composition of OM (Cunliffe et al., 2013). In calm conditions, bacteria accumulate in the SML (Rahlff et al., 2017) and are an integral part of the biofilm-like habitat forming at the air-sea interface (Stolle et al., 2010; Wurl et al., 2016).

A variety of specific organic compounds such as surfaceactive substances (SASs), volatile organic compounds (VOCs) and acidic polysaccharides aggregating to transparent exopolymer particles (TEPs) strongly influence the physicochemical properties of OM in the SML. SASs (or surfactants) are highly enriched in the SML relative to bulk water and contribute to the formation of surface films (Frka et al., 2009, 2012; Wurl et al., 2009). SASs are excreted by phytoplankton, during zooplankton grazing and bacterial activities (e.g., Gašparović et al., 1998b). The enrichment of SASs in the SML occurs predominantly via advective and diffusive transport at low wind speeds or bubble scavenging at moderate to high wind speeds (Wurl et al., 2011). When transferred to the atmosphere, OM with surfactant properties, ubiquitously present in atmospheric aerosol particles, has the potential to affect the cloud droplet formation ability of these particles (e.g., Kroflič et al., 2018).
Sticky and gel-like TEPs are secreted by phytoplankton and bacteria and can form via abiotic processes (Wurl et al., 2009). Depending on their buoyancy they may contribute to sinking particles (marine snow) or can rise and accumulate at the sea surface. Due to their sticky nature, TEPs are called "marine glue", and as such they contribute to the formation of hydrophobic films by trapping other particulate and dissolved organic compounds (Wurl et al., 2016). Additionally, TEPs are suspected to play a pivotal role in the release of marine particles into the air via sea spray and bursting bubbles (Bigg and Leck, 2008).

Many studies recognize a possible link between marine biological activity and marine-derived organic aerosol particles (Facchini et al., 2008; O'Dowd et al., 2004; Ovadnevaite et al., 2011) and thus to the SML due to the linkages outlined before. Yet, the environmental drivers and mechanisms for OM enrichment are not very clear (Brooks and Thornton, 2018; Gantt and Meskhidze, 2013), and individual compound studies can only explain a small part of OM cycling (e.g., van Pinxteren et al., 2017; van Pinxteren and Herrmann, 2013). The molecular understanding of the occurrence and processing of OM in all marine compartments is essential for a deeper understanding and for an evidencebased implementation of organic aerosol particles and their relations to the oceans in coupled ocean-atmosphere models. Synergistic measurements in comprehensive interdisciplinary field campaigns in representative areas of the ocean and also laboratory studies under controlled conditions are required to explore the biology, physics and chemistry in all marine compartments (e.g., Quinn et al., 2015).

Accordingly, the project MarParCloud (Marine biological production, organic aerosol Particles and marine Clouds: a process chain) addresses central aspects of oceanatmosphere interactions focusing on marine OM within an interdisciplinary field campaign at the Cape Verde islands that took place from 13 September to 13 October 2017. Together with contributions from the Research and Innovation Staff Exchange EU project MARSU (MARine atmospheric Science Unravelled: Analytical and mass spectrometric techniques development and application), synergistic measurements will deliver an improved understanding of the role of marine organic matter. MarParCloud focuses on the following main research questions.

- To what extent is seawater a source of OM to aerosol particles (regarding number, mass, chemical composition, CCN and INP concentration) and in cloud water?

- What are the important chemically defined OM groups (proteins, lipids, carbohydrates - as sum parameters and on a molecular level) in oceanic surface films, aerosol particles and cloud water, and how are they linked?

- What are the main biological and physical factors responsible for the occurrence and accumulation of OM 
in the surface film and in other marine compartments (aerosol particles, cloud water)?

- What functional role do bacteria play in aerosol particles?

- Does the SML contribute to the formation of ice nuclei, and at what temperatures do these nuclei become iceactive? Are these ice nuclei found in cloud water?

- Does the presence of marine OM in the surface ocean drive the concentration of CCN in the MBL?

- How must an emission parameterization for OM (including individual species) be designed in order to best reflect the concentrations in the aerosol depending on those in seawater or biological productivity under given ambient conditions?

The tropics, with high photochemical activity, are of central importance in several aspects of the climate system. Approximately $75 \%$ of the tropospheric production and loss of ozone occurs within the tropics, in particular in the tropical upper troposphere (Horowitz et al., 2003). The Cape Verde islands are located downwind of the Mauritanian coastal upwelling region northwest of the islands. In addition, they are in a region of the Atlantic that is regularly impacted by dust deposition from the African Sahara (Carpenter et al., 2010). The remote station of CVAO is therefore an excellent site for process-oriented campaigns embedded into long-term measurements of atmospheric constituents, which are essential for understanding atmospheric processes and their impact on climate.

\section{Strategy of the campaign}

The present contribution intends to provide an introduction, overview and first results of the comprehensive MarParCloud field campaign to the MarParCloud Special Issue. We will describe the oceanic and atmospheric ambient conditions at the CVAO site that have not been synthesized elsewhere and are valuable in themselves because of the sparseness of the existing information at such a remote tropical location. Next, we will describe the sampling and analytical strategy during MarParCloud, taking into account all marine compartments, i.e., the seawater (SML and bulk water), ambient aerosol particles (at ground level and Mt. Verde, elevation: $744 \mathrm{~m}$ a.s.l.) and cloud water. Detailed aerosol investigations were carried out for both the chemical composition and physical properties at both stations. In addition, vertical profiles of meteorological parameters were measured at CVAO using a helikite. These measurements were combined with modeling studies to determine the MBL height. In conjunction, they are an indicator for the mixing state within the MBL, providing further confidence for ground-level-measured aerosol properties being representative for those at cloud level. The chemical characterization of $\mathrm{OM}$ in the aerosol particles as well as in the surface ocean and cloud water included sum parameters (e.g., OM classes like biopolymers and humiclike substances) and molecular analyses (e.g., lipids, sugars and amino acids). Additionally, to address direct oceanic transfer (bubble bursting), seawater and aerosol particle characterizations obtained from a systematic plunging waterfall tank are presented. Ocean surface mercury $(\mathrm{Hg})$ associated with OM was investigated. Marine pigments and marine microorganisms were analyzed to investigate their relation to $\mathrm{OM}$ and to algae-produced trace gases. Marine trace gases such as dimethyl sulfide (DMS), other VOCs and oxygenated $(\mathrm{O})$ VOCs were measured and discussed. Furthermore, a series of continuous nitrous acid (HONO) measurements was conducted at the CVAO with the aim of elucidating the possible contribution of marine surfaces to the production of this acid. To explore whether marine air masses exhibit significant potential to form SOA, an oxidation flow reactor (OFR) was deployed at the CVAO. Finally, modeling studies to describe the vertical transport of selected marine organic compounds from the ocean to the atmosphere up to cloud, level taking into account advection and wind conditions, will be applied. From the obtained results of organic compound measurements, a new source function for the oceanic emission of OM will be developed. The measurements, first interpretations and conclusions aggregated here will provide a basis for upcoming detailed analysis.

\section{Experimental design}

\subsection{General CVAO site and meteorology}

The Cape Verde archipelago islands are situated in the eastern tropical North Atlantic (ETNA). The archipelago experiences strong northeast trade winds that divide the islands into two groups, the Barlavento (windward) and Sotavento (leeward) islands. The northwestern Barlavento islands of São Vicente and Santo Antão, as well as São Nicolau, are rocky and hilly, making them favorable for the formation of orographic clouds.

The CVAO is part of a bilateral initiative between Germany and the UK to conduct long-term studies in the tropical northeast Atlantic Ocean $\left(16^{\circ} 51.49^{\prime} \mathrm{N},-24^{\circ} 52.02^{\prime} \mathrm{E}\right)$. The station is located directly at the shoreline at the northeastern tip of the island of São Vicente at $10 \mathrm{~m}$ a.s.l.

The air temperature varies between 20 and $30^{\circ} \mathrm{C}$ with a mean of $23.6^{\circ} \mathrm{C}$. The relative humidity is on average $79 \%$ and precipitation is very low (Carpenter et al., 2010). Due to the trade winds, this site is free from local island pollution and provides reference conditions for studies of oceanatmosphere interactions. However, it also lies within the Saharan dust outflow corridor to the Atlantic Ocean and experiences strong seasonal dust outbreaks with peaks between late November and February (Fomba et al., 2014; Patey et al., 
2015; Schepanski et al., 2009). Air mass inflow to this region can vary frequently within a day, leading to strong inter-day temporal variation in the aerosol mass and chemical composition (Fomba et al., 2014; Patey et al., 2015).

Despite the predominant NE trade winds, air masses from the USA and from Europe are partly observed. However, during autumn, marine air masses are mainly present with few periods of dust outbreaks because at these times the dust is transported at higher altitudes in the Saharan air layer (SAL) over the Atlantic to the Americas (Fomba et al., 2014). During autumn, there is no significant transport of the dust at lower altitudes, and only intermittent effects of turbulence in the SAL lead to occasional dust deposition and sedimentation from the SAL to lower altitudes and at ground level. Furthermore, during autumn the mountain site (Mt. Verde) is often covered with clouds as surface temperatures drop after typically very hot summer months. Due to the frequent cloud coverage and less dust influence in autumn, the MarParCloud campaign was scheduled from 13 September to 13 October 2017.

\subsection{CVAO equipment during MarParCloud}

The setup of the CVAO station is explained in detail in Carpenter et al. (2010) and Fomba et al. (2014). During the MarParCloud campaign, the $30 \mathrm{~m}$ high tower was equipped with several aerosol particle samplers, including high-volume $\mathrm{PM}_{1}, \mathrm{PM}_{10}$ (Digitel, Riemer, Germany) and total suspended particulate (TSP; Sierra Anderson, USA) samplers, low-volume TSP (home-built) and $\mathrm{PM}_{1}$ (ComdeDerenda, Germany) samplers, and a size-resolved aerosol particle Berner impactor (five stages). The sampling times were usually set to $24 \mathrm{~h}$ (more details in the Supplement). Online aerosol instruments included a cloud condensation nuclei counter (CCNC; Droplet Measurement Technologies, Boulder, USA) (Roberts and Nenes, 2005) to measure the cloud condensation nuclei number concentration $\left(N_{\mathrm{CCN}}\right)$. A TROPOS-type scanning mobility particle sizer (SMPS) (Wiedensohler et al., 2012) and an APS (aerodynamic particle sizer; model 3321, TSI Inc., Paul, MN, USA) with a $\mathrm{PM}_{10}$ inlet were used to measure the size range from $10 \mathrm{~nm}$ to $10 \mu \mathrm{m}$. The particles hygroscopicity (expressed as $\kappa$; Petters and Kreidenweis, 2007) was derived from combined $N_{\mathrm{CCN}}$ and particle number size distribution (PNSD) measurements from the SMPS and APS. Vertical profiles of meteorological parameters were measured using a $16 \mathrm{~m}^{3}$ helikite (Allsopp Helikites Ltd, Hampshire, UK), a combination of a kite and a tethered balloon. Additional equipment at the CVAO station on the ground included a plunging waterfall tank, a long-path absorption photometer (LOPAP) and a Gothenburg potential aerosol mass reactor (Go : PAM) chamber. Further details on the measurements are listed and explained in the Supplement, and all instruments can be found in Table S1.

\subsection{Mt. Verde}

Mt. Verde was a twin site for aerosol particle measurements and the only site with cloud water sampling during the MarParCloud campaign. It is the highest point of São Vicente island $(744 \mathrm{~m})$, situated in the northeast of the island $\left(16^{\circ} 86.95^{\prime} \mathrm{N},-24^{\circ} 93.38^{\prime} \mathrm{E}\right)$ and northwest of the CVAO. Mt. Verde also experiences direct trade winds from the ocean with no significant influence of anthropogenic activities from the island. Mt. Verde was in clouds during roughly $58 \%$ of the campaign. However, the duration of the cloud coverage varied between 2 and $18 \mathrm{~h}$, with longer periods of cloud coverage observed in the nights when surface temperatures dropped.

During the campaign, Mt. Verde was, for the first time, equipped with similar collectors as operated at the CVAO, namely a high-volume Digitel sampler for $\mathrm{PM}_{1}$ and $\mathrm{PM}_{10}$ bulk aerosol particles, a low-volume TSP sampler, and a fivestage Berner impactor for size-resolved aerosol particle sampling. Bulk cloud water was collected using six (four plastic and two stainless steel) compact Caltech active strand cloud water collectors (CASCC2) (Demoz et al., 1996). The six samplers were run in parallel for a sampling time between 2.5 and $13 \mathrm{~h}$ collecting between 78 and $544 \mathrm{~mL}$ of cloud water per sampler in an acid-precleaned plastic bottle. It needs to be pointed out that the aerosol particle samplers run continuously and aerosol particles were also sampled during cloud events. The cloud droplets were efficiently removed due to the preconditioning of the aerosol particles sampled with the Berner impactor (more information in the Supplement) and due to the size cut the $\mathrm{PM}_{1}$ sampler. However, for aerosol particles sampled with the $\mathrm{PM}_{10}$ sampler, small cloud droplets can be collected as well. In addition, the particles sampled with the low-volume TSP sampler can be influenced by cloud droplets to some extent. The cloud liquid water content was measured continuously by a particle volume monitor (PVM-100, Gerber Scientific, USA), which was mounted on a support at the same height as the cloud water samplers. The same suite of online aerosol instruments as employed at the CVAO (SMPS, APS, CCNC) was installed at the mountainside. All instruments employed at the Mt. Verde site are listed in Table S2.

\subsection{Oceanographic setting and seawater sampling site}

The ETNA around Cape Verde is characterized by a socalled oxygen minimum zone (OMZ) at a water depth of approximately $450 \mathrm{~m}$ and by sluggish water velocities (Brandt et al., 2015). The region is bounded by a highly productive eastern boundary upwelling system (EBUS) along the African coast, by the Cape Verde Frontal Zone (CVFZ) on its western side and by zonal current bands towards the Equator (Stramma et al., 2005). Upper water masses towards the archipelago are dominated by North Atlantic Central Water (NACW) masses with enhanced salinity, whereas the 
South Atlantic Central Water (SACW) mass is the dominating upper-layer water mass in the EBUS region (Pastor et al., 2008). Filaments and eddies generated in the EBUS region propagate westwards into the open ocean and usually dissipate before reaching the archipelago. However, observations from the Cape Verde Ocean Observatory (CVOO) $60 \mathrm{nmi}$ northeast of São Vicente island $\left(17^{\circ} 35.00^{\prime} \mathrm{N},-24^{\circ} 17.00^{\prime} \mathrm{E}\right.$; http://cvoo.geomar.de, last access: 10 April 2020) also revealed the occurrence of water masses originating from the EBUS region that were advected by stable mesoscale eddies (Fiedler et al., 2016; Karstensen et al., 2015).

For the MarParCloud campaign, the water samples were taken at Baía das Gatas, a beach that is situated upwind of the CVAO about $4 \mathrm{~km}$ northwest in front of the station. The beach provided shallow access to the ocean that allowed the employment of fishing boats for manual SML and bulk water sampling as well as the other equipment. For SML sampling, the glass plate technique as one typical SML sampling strategy was applied (Cunliffe and Wurl, 2014). A glass plate with a sampling area of $2000 \mathrm{~cm}^{2}$ was vertically immersed into the water and then slowly drawn upwards with a withdrawal rate between 5 and $10 \mathrm{~cm} \mathrm{~s}^{-1}$. The surface film adheres to the surface of the glass and is removed using framed Teflon wipers (Stolle et al., 2010; van Pinxteren et al., 2012). Bulk seawater was collected from a depth of $1 \mathrm{~m}$ using a specially designed device consisting of a glass bottle mounted on a telescopic rod used to monitor sampling depth. The bottle was opened underwater at the intended sampling depth with a specifically conceived seal-opener.

In addition, the MarParCat, a remotely controllable catamaran, was applied for SML sampling using the same principle as manual sampling (glass plate). The MarParCat sampled bulk water in a depth of $70 \mathrm{~cm}$. A more detailed description of the MarParCat can be found in the Supplement. Using the two techniques, manual sampling and the MarParCat, between 1 and $6 \mathrm{~L}$ of SML was sampled at each sampling event. For the sampling of the SML, great care was taken that all parts in contact with the sample (glass plate, bottles, catamaran tubing) underwent an intense cleaning with $10 \% \mathrm{HCl}$ to avoid contamination and carryover problems.

The sampling sites with the different setup and equipment are illustrated in Fig. 1. All obtained SML and bulk water samples and their standard parameters are listed in Table S3.

\section{Ambient conditions}

\subsection{Atmospheric conditions during the campaign}

\subsubsection{Marine and dust influences}

During autumn, marine background air masses are mainly observed at the CVAO, interrupted by a few periods of dust outbreaks (Carpenter et al., 2010; Fomba et al., 2014). A 5year average dust record showed low concentrations with av- erage values of 25 and $17 \mu \mathrm{g} \mathrm{m}^{-3}$ during September and October, respectively (Fomba et al., 2014). The dust concentrations during the campaign were generally $<30 \mu \mathrm{g} \mathrm{m}^{-3}$; however, strong temporal variation of mineral dust markers was observed (Table 1). According to Fomba et al. (2013, 2014), a classification into marine conditions (dust $<5 \mu \mathrm{g} \mathrm{m}^{-3}$, typically $\mathrm{Fe}<50 \mathrm{ng} \mathrm{m}^{-3}$ ), low dust (dust $<20 \mu \mathrm{g} \mathrm{m}^{-3}$ ) and moderate dust (dust $<60 \mu \mathrm{g} \mathrm{m}^{-3}$ ) conditions was used to describe the dust influence during this period. Following this classification, one purely marine period was defined from 22 to 24 September, which was also evident from the course of the back trajectories (Fig. S1). For the other periods, the air masses were classified as mixed with marine and low or moderate dust influences as listed in Table 1. Based on a three-modal parameterization method that regarded the number concentrations in different aerosol particle modes, a similar but much finer classification of the aerosol particles was obtained as discussed in Gong et al. (2020a).

The classification of air masses was complemented by air mass backward trajectory analyses; $96 \mathrm{~h}$ back trajectories were calculated on an hourly basis within the sampling intervals using the HYSPLIT model (HYbrid SingleParticle Lagrangian Integrated Trajectory; http://www.arl. noaa.gov/ready/hysplit4.html, last access: 26 July 2019) published by the National Oceanic and Atmospheric Administration (NOAA) in the ensemble mode at an arrival height of $500 \mathrm{~m} \pm 200 \mathrm{~m}$ (van Pinxteren et al., 2010). The back trajectories for the individual days of the entire campaign, based on the sampling interval for aerosol particle sampling, were calculated and are listed in Fig. S1. Air parcel residence times over different sectors are plotted in Fig. 2. The comparison of dust concentration and the residence time of the back trajectories revealed that in some cases low dust contributions were observed although the air masses traveled almost completely over the ocean (e.g., the first days of October). In such cases, the entrainment of dust from higher altitudes might explain this finding. The related transport of Saharan dust to the Atlantic during the measurement period can be seen in a visualization based on satellite observations (https://svs.gsfc.nasa.gov/12772, last access: 1 October 2019). For specific days with a low MBL height, it might be more precise to employ back trajectories that start at a lower height and therefore exclude entrainment effects from the free troposphere for the characterization of CVAO data. Similarly, for investigating long-lived components, it might be helpful to analyze longer trajectory integration times (e.g., $10 \mathrm{~d}$ instead of $4 \mathrm{~d}$ ). However, the longer the back trajectories, the higher the level of uncertainty. Regarding aerosol analysis, it is important to notice that dust influences are generally more pronounced on supermicron particles than on submicron particles (e.g., Fomba et al., 2013; Müller et al., 2009, 2010), meaning that bigger particles may be affected by dust sources, whereas smaller particles may have stronger oceanic and anthropogenic as well as long-range transport influences. Consequently, the classification presented herein represents 


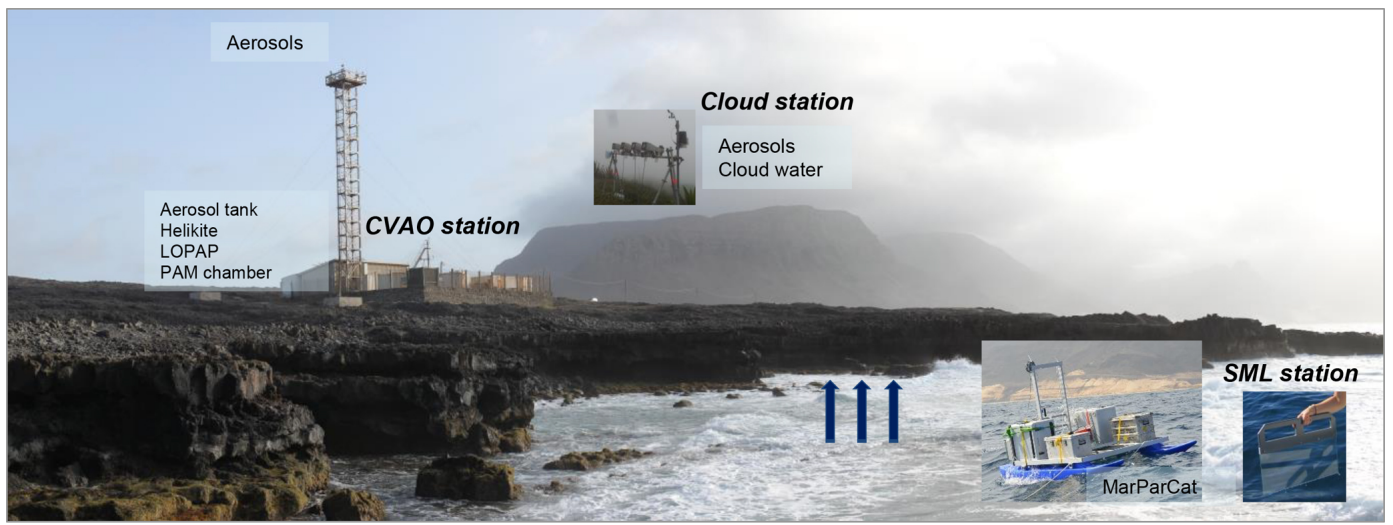

Figure 1. Illustration of the different sampling sites during the campaign.

Table 1. Classification of the air masses according to dust concentrations from the impactor samples after the calculation of dust concentrations according to the Fomba et al. (2014) sample and under the consideration of backward trajectories (Fig. 2).

\begin{tabular}{|c|c|c|c|}
\hline $\begin{array}{l}\text { Start local time } \\
(\text { yyyy/mm/dd, UTC-1) }\end{array}$ & $\begin{array}{l}\text { Stop local time } \\
\text { (yyyy/mm/dd, UTC-1) }\end{array}$ & $\begin{array}{r}\text { Dust conc. } \\
\left(\mu \mathrm{g} \mathrm{m}^{-3}\right)\end{array}$ & Classification \\
\hline 2017/09/18 18:18:00 & 2017/09/19 14:57:00 & 53.5 & Moderate dust \\
\hline 2017/09/19 16:30:00 & 2017/09/20 15:30:00 & 38.2 & Moderate dust \\
\hline 2017/09/20 18:00:00 & 2017/09/21 14:00:00 & 30.0 & Moderate dust \\
\hline 2017/09/21 15:00:00 & 17/09/22 15:00:00 & 14.5 & Low dust \\
\hline 2017/09/22 16:15:00 & $17 / 09 / 24$ 16:46:00 & 4.1 & Marine \\
\hline 2017/09/24 17:30:00 & 17/09/25 14:30:00 & 2.2 & Marine \\
\hline 2017/09/25 16:00:00 & 2017/09/26 15:00:00 & 11.6 & Low dust \\
\hline $2017 / 09 / 26$ 15:51:33 & 17/09/27 14:45:00 & 37.6 & Moderate dust \\
\hline 2017/09/27 15:30:00 & 17/09/28 16:30:00 & 20.6 & Moderate dust \\
\hline 2017/09/28 18:10:00 & $17 / 09 / 30$ 15:45:00 & 27.3 & Moderate dust \\
\hline 2017/09/30 17:05:00 & 2017/10/01 14:15:00 & 42.7 & Moderate dust \\
\hline 2017/10/01 15:00:00 & 2017/10/02 14:30:00 & 35.5 & Moderate dust \\
\hline 2017/10/02 15:42:00 & 17/10/03 14:53:00 & 29.1 & Moderate dust \\
\hline 2017/10/03 15:45:00 & 017/10/04 14:30:00 & 14.8 & Low dust \\
\hline 2017/10/04 15:27:00 & 2017/10/05 15:18:00 & 13.2 & Low dust \\
\hline 2017/10/05 16:10:00 & 2017/10/06 14:54:00 & 17.2 & Low dust \\
\hline 2017/10/06 16:00:00 & 2017/10/07 15:30:00 & 17.0 & Low dust \\
\hline & & 16.8 & Low dust \\
\hline 2017/10/09 18:13:00 & 2017/10/10 15:00:00 & 27.6 & Moderate dust \\
\hline
\end{tabular}

a first general characterization of air mass origins. Depending on the sampling periods of other specific analyses, slight variations may be observed, and this will be indicated in the specific analysis and manuscripts.

\subsubsection{Meteorological conditions}

Air temperature, wind direction and wind speed measured between 15 September and 6 October $(17.5 \mathrm{~m}$ a.s.l.) are shown in Fig. 3 together with the mixing ratios of the trace gases ozone, ethane, ethene, acetone, methanol and DMS. During this period the air temperature ranged from $25.6^{\circ} \mathrm{C}$ (06:00 UTC) to $28.3^{\circ} \mathrm{C}$ (14:00 UTC) with an average diurnal variation of $0.6^{\circ} \mathrm{C}$. The wind direction was northeasterly

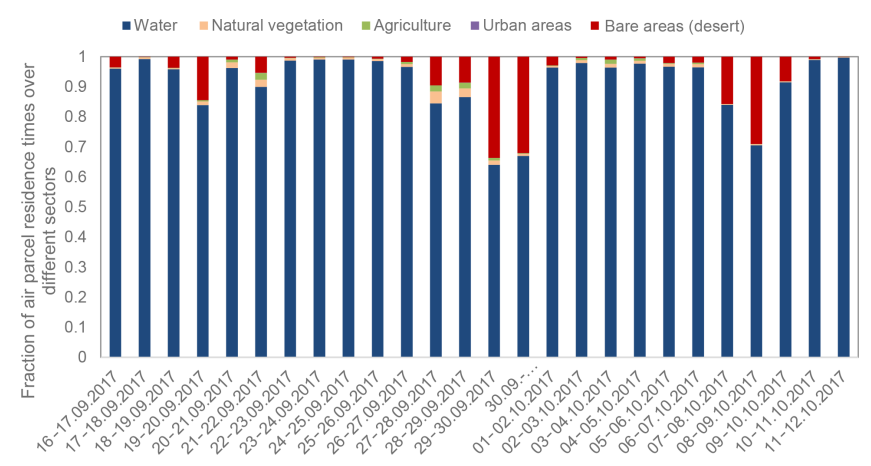

Figure 2. The residence time of the air masses calculated from $96 \mathrm{~h}$ (4 d) back trajectories in ensemble mode. 
(30 to $60^{\circ}$ ), except for a period between 19 and 20 September and again on 21 September when northerly air and lower wind speeds prevailed. The meteorological conditions observed during the campaign were typical for this site (e.g., Carpenter et al., 2010; Fomba et al., 2014). The concentrations of the different trace gases will be more thoroughly discussed in Sect. 5.3.

\subsubsection{Measured and modeled marine boundary layer (MBL) height}

The characterization of the MBL is important for the interpretation of both ground-based and vertically resolved measurements because the MBL mixing state allows us to elucidate the possible connections between ground-based processes (e.g., aerosol formation) and the higher (e.g., mountain and cloud level) altitudes. The Cape Verde islands typically exhibit a strong inversion layer with a sharp increase in the potential temperature and a sharp decrease in the humidity (Carpenter et al., 2010).

Vertical measurements of meteorological parameters were carried out at CVAO with a $16 \mathrm{~m}^{3}$ helikite. The measurements demonstrate that a helikite is a reliable and useful instrument that can be deployed under prevailing wind conditions such as at this measurement site. A total of 19 profiles on 10 different days could be obtained, and Fig. 4 shows an exemplary profile from 17 September. During the campaign, the wind speed varied between 2 and $14 \mathrm{~m} \mathrm{~s}^{-1}$, and the MBL height was found to be between about 600 and $1100 \mathrm{~m}$ (compare to Fig. 5). Based on the measured vertical profiles, the MBL was found to often be well mixed. However, there are indications for a decoupled boundary layer in a few cases that will be further analyzed.

As it was not possible to obtain information on the MBL height for the entire campaign from online measurements, the MBL height was also simulated using the bulk Richardson number. The simulations showed that the MBL height was situated where the bulk Richardson number exceeded the critical value of 0.25 . Figure 5 shows that the simulated MBL height was always lower compared to the measured one during the campaign and also compared to previous measurements reported in the literature. Based on long-term measurements, Carpenter et al. (2010) observed an MBL height of $713 \pm 213 \mathrm{~m}$ at Cape Verde. In the present study a simulated MBL height of $452 \pm 184 \mathrm{~m}$ was found but covering solely a period over 1 month. The differences might be caused by the grid structure of the applied model (more details in the Supplement). The vertical resolution of 100 to $200 \mathrm{~m}$ might lead to a misplacement of the exact position of the MBL height. Moreover, the model calculations were constructed to identify the lowest inversion layer. Therefore, the modeled MBL height might represent a low, weak internal layer within the MBL and not the actual MBL. These issues will be analyzed in further studies.

\subsubsection{Cloud conditions}

The Cape Verde islands are dominated by a marine tropical climate, and as mentioned above, marine air is constantly supplied from a northeasterly direction, which also transports marine boundary layer clouds towards the islands. Average wind profiles derived from European Centre for MediumRange Weather Forecasts (ECWMF) model simulations are shown in Fig. 6a. On the basis of the wind profiles, different cloud scenes have been selected and quantified (Derrien and Le Gleau, 2005) using geostationary Meteosat SEVIRI data with a spatial resolution of $3 \mathrm{~km}$ (Schmetz et al., 2002); these are shown in Fig. 6b-f. The island São Vicente is located in the middle of each picture. The first scene at 10:00 UTC on 19 September was characterized by low wind speeds throughout the atmospheric column (Fig. 6b). In this calm situation, a compact patch of low-level clouds was located northwest of the Cape Verde islands. The cloud field was rather spatially homogeneous, i.e., marine stratocumulus, which transitioned to more broken cumulus clouds towards the island. Southeastwards of the islands, high-level ice clouds dominated and possibly mask lower-level clouds. For the second cloud scene at 10:00 UTC on 22 September (Fig. 6c), wind speed was higher at more than $12 \mathrm{~m} \mathrm{~s}^{-1}$ in the boundary layer. Similarly, coverage of low-level to very low-level clouds was rather high in the region around Cape Verde. A compact stratocumulus cloud field approached the islands from the northeasterly direction. The clouds that had formed over the ocean dissolved when the flow traversed the islands. Pronounced lee effects appeared downstream of the islands. Cloud scene three at 10:00 UTC on 27 September was again during a calm phase with a wind speed of only a few meters per second (Fig. 6d). The scene was dominated by fractional clouds (with a significant part of the spatial variability close to or below the sensor resolution). These clouds formed locally and grew. The advection of clouds towards the islands was limited. The last two cloud scenes (at 10:00 UTC on 1 October in Fig. 6e and at 10:00 UTC on 11 October in Fig. 6f) were shaped by higher boundary layer winds and changing wind directions in higher atmospheric levels. The scene in Fig. 6e shows a complex mixture of low-level cloud fields and higher-level cirrus patches. The scene in Fig. 6f was again dominated by low-level to very low-level clouds. The eastern part of the islands was embedded in a rather homogeneous stratocumulus field. A transition of the spatial structure of the cloud field happened in the center of the domain, with more cumuliform clouds and cloud clumps west of the Cape Verde islands. Overall, the majority of low-level clouds over the islands were formed over the ocean, and ocean-derived aerosol particles, e.g., sea salt and marine biogenic compounds, might be expected to have some influence on cloud formation. Infrequent instances of locally formed clouds influenced by the orography of the islands could be also identified in the satellite data The different cloud scenes reflect typical situations observed 


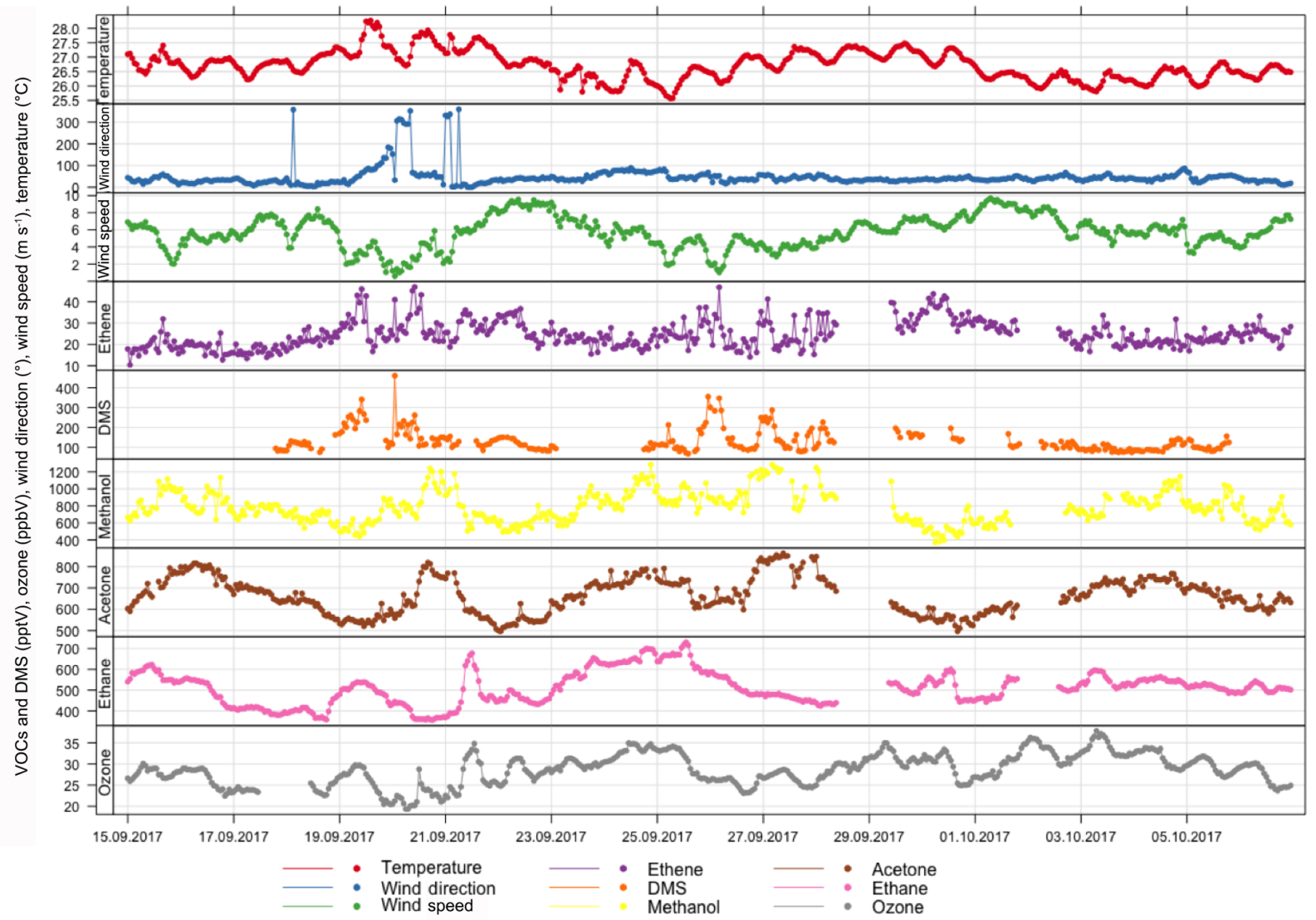

Figure 3. Time series of air temperature, wind direction, wind speed, ethene, dimethyl sulfide, methanol, acetone, ethane and ozone.

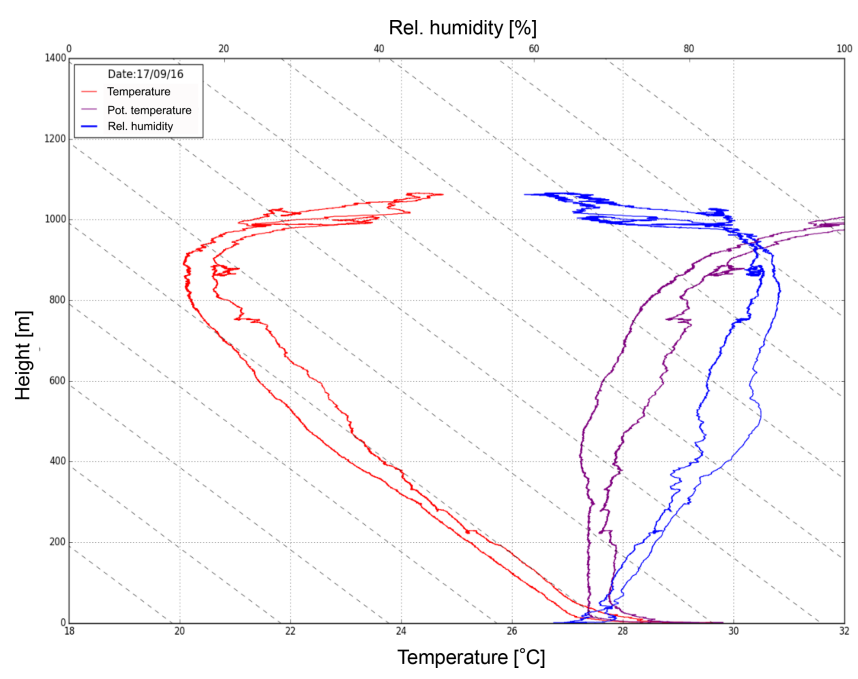

Figure 4. The measured temperature and humidity profiles at the CVAO on 17 September using a $16 \mathrm{~m}^{3}$ helikite. From the measurements the boundary layer height was determined (here: $\sim 850 \mathrm{~m}$ ). This figure was adapted from Fig. S3 in Gong et al. (2020a).

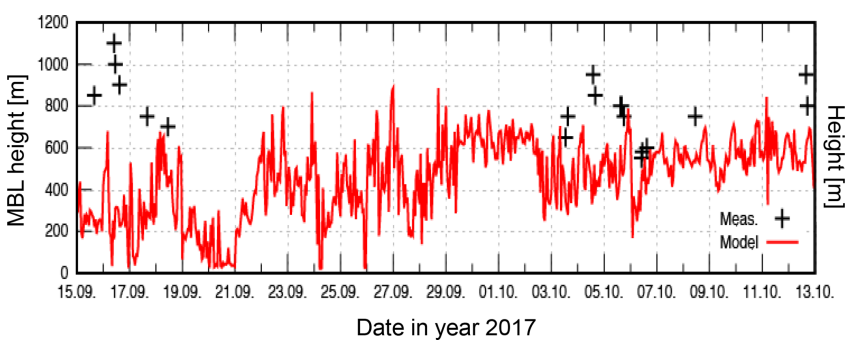

Figure 5. Time series and vertical profiles of the MBL height simulated with COSMO-MUSCAT on the second inner nest with a grid spacing of $0.875 \mathrm{~km}$ (N2 domain) and measured with the helikite.

in conditions with either weaker or stronger winds. The average in-cloud time of an air parcel might depend on cloud type and cloud cover, which in turn impacts in-cloud chemical processes (e.g., Lelieveld and Crutzen, 1991), such as the formation of methane-sulfonic acid and other organic acids (Hoffmann et al., 2016; Chen et al., 2018). Future studies will relate the chemical composition of the aerosol particles and cloud water to the cloud scenes and their respective oxidation capacity. However, the rather coarse horizontal resolution of the satellite sensor and missing information about the time-resolved vertical profiles of thermodynamics and cloud 
condensate limit a further detailed characterization of these low-level cloud fields and their formation processes. A synergistic combination with ground-based in situ and remote sensing measurements would be highly beneficial for future investigations to elucidate how cloud chemistry might be different for the varying cloud scenes depending on horizontal cloud patterns and vertical cloud structures.

\subsection{Biological seawater conditions}

\subsubsection{Pigment and bacteria concentration in seawater}

To characterize the biological conditions at CVAO, a variety of pigments including chlorophyll $a$ (chl $a$ ) were measured in the samples of Cape Verde bulk water (data in Table S4 and illustrated in Sect. 5.4.1). Chl $a$ is the most prominently used tracer for biomass in seawater; however, information on phytoplankton composition can only be determined by also determining marker pigments. Therefore, each time when a water sample was taken, several liters of bulk water were also collected for pigment analysis (more details in the Supplement). Chl $a$ concentrations varied between 0.11 and $0.6 \mu \mathrm{g} \mathrm{L}^{-1}$ and are more thoroughly discussed together with the pigment composition in Sect. 5.4.1. Moreover, as organisms other than phytoplankton can contribute to the OM pool, bacterial abundance was analyzed in the SML and bulk water samples, and these data are reported in Sect. 5.7.3.

\subsubsection{Wave glider fluorescence measurements}

Roughly at the same time as the MarParCloud field campaign took place, an unmanned surface vehicle (SV2 wave glider, Liquid Robotics Inc.) equipped with a biogeochemical sensor package, a conductivity-temperature-depth sensor (CTD) and a weather station was operated in the vicinity of the sampling location. The wave glider carried out continuous measurements of surface water properties (water intake depth: $0.3 \mathrm{~m}$ ) along a route near the coast (Fig. $7 \mathrm{a}$ ), and on 5 October it was sent on a transect from close to the sampling location towards the open ocean in order to measure lateral gradients in oceanographic surface conditions.

The glider measurements delivered information on the spatial resolution of several parameters. Fluorescence measurements, which can be seen as a proxy for chl $a$ concentration in surface waters and hence for biological production, indicated some enhanced production leeward of the islands and also at one location upwind of the island of Santa Luzia next to São Vicente. In the vicinity of the MarParCloud sampling site the glider observed a slight enhancement in fluorescence when compared to open-ocean waters. This is in agreement with the measured pigment concentration. The overall pattern of slightly enhanced biological activity was also confirmed by the MODIS Terra satellite fluorescence measurements (Fig. 7b). However, both in situ glider and sample data as well as remote sensing data did not show any particularly strong coastal bloom events and thus indicate that the MarParCloud sampling site represented the open-ocean regime well during the sampling period.

\section{Measurements and selected results}

\subsection{Vertical resolution measurements}

\subsubsection{Physical aerosol characterization}

Based on aerosol particles measured during the campaign, air masses could be classified into different types depending on differences in PNSDs. Marine-type and dust-type air masses could be clearly distinguished, even if the measured dust concentrations were only low to medium according to the annual mean at the CVAO (Fomba et al., 2013, 2014). The median of PNSDs during marine conditions is illustrated in Fig. 8 and showed three modes, i.e., Aitken, accumulation and coarse mode. There was a minimum between the Aitken and accumulation mode of PNSDs (Hoppel minimum; see Hoppel et al., 1986) at roughly $70 \mathrm{~nm}$. PNSDs measured in marine-type air masses featured the lowest Aitken-, accumulation- and coarse-mode particle number concentrations, with median values of 189,143 and $7 \mathrm{~cm}^{-3}$, respectively. The PNSDs present during times with dust influences featured a single mode in the submicron size range (Fig. 8), and no visible Hoppel minimum was found. The dust-type air masses featured the highest total particle number concentration $\left(994 \mathrm{~cm}^{-3}\right)$ and a median coarse-mode particle number concentration of $44 \mathrm{~cm}^{-3}$.

$N_{\mathrm{CCN}}$ values at different supersaturations were compared during dust and marine periods, as shown in Fig. 9. During dust periods, the aerosol particles show a great enhancement in Aitken-, accumulation- and coarse-mode number concentrations such that overall $N_{\mathrm{CCN}}$ increases distinctly. $N_{\mathrm{CCN}}$ at a supersaturation of $0.30 \%$ (proxy for the supersaturation encountered in clouds present during the campaign) during the strongest observed dust periods is about 2.5 times higher than that during marine periods. The fraction of sea spray aerosol, i.e., primary aerosol originating from the ocean, was determined based on three-modal fits from which the particle number concentrations in the different modes were determined (Modini et al., 2015; Wex et al., 2016; Quinn et al., 2017). The SSA mode in this study coved a size range from $\sim 30 \mathrm{~nm}$ to $10 \mu \mathrm{m}$ with a peak at $\sim 600 \mathrm{~nm}$ (Fig. 8b). More details on the method and calculations are given in Gong et al. (2020a). During marine periods, SSA accounted for about $3.7 \%$ of CCN number concentrations at $0.30 \%$ supersaturation and for $1.1 \%$ to $4.4 \%$ of $N_{\text {total }}$ (total particle number concentration). The hygroscopicity parameter kappa $(\kappa)$ averaged 0.28 , suggesting the presence of OM in the particles (see Gong et al., 2020a). Particle sizes for which $\kappa$ was determined (i.e., the critical diameters determined during $\mathrm{CCN}$ 


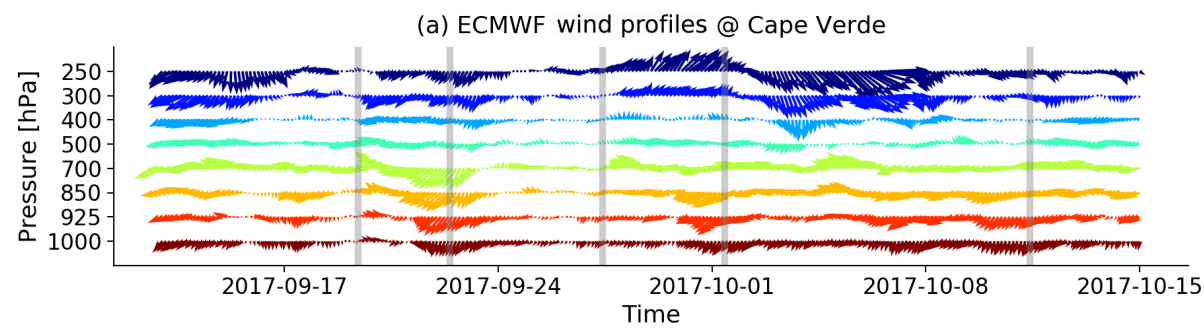

(b) 2017-09-19 10:00 UTC (c) 2017-09-22 10:00 UTC (d) 2017-09-27 10:00 UTC

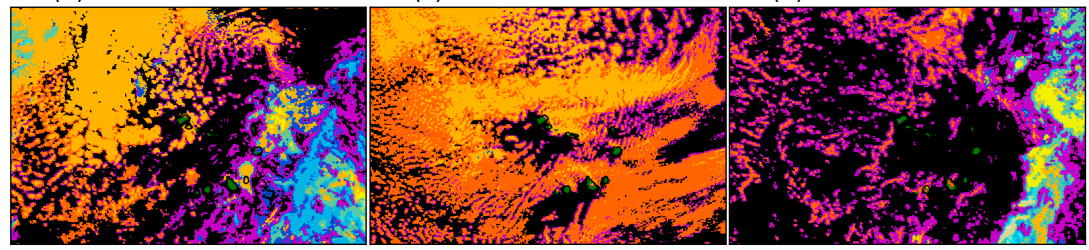

(e) 2017-10-01 10:00 UTC

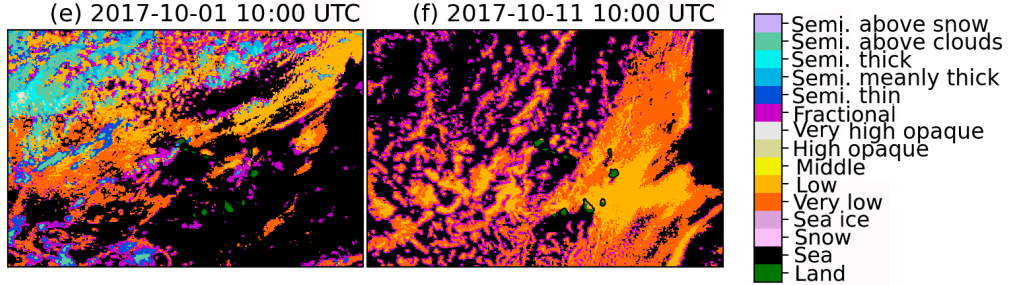

Figure 6. (a) ECMWF wind forecasts and (b-f) cloud scenery derived from Meteosat SEVIRI observations for the Cape Verde islands region using a state-of-the-art cloud classification algorithm (the cloud retrieval software of the Satellite Application Facility, with support for Nowcasting and Very Short-Range Forecasting version 2016. (a) Average horizontal winds have been derived from a $2.5 \times 2.5^{\circ}(250 \mathrm{~km} \times 25 \mathrm{~km})$ domain centered on the Cape Verde islands and are plotted for each pressure level from 1000 to $250 \mathrm{hPa}$ against time using arrows. The arrow colors refer to the pressure level. Gray vertical lines mark the times of the subsequently shown cloud scenes. (b-f) Different cloud scenes observed with Meteosat SEVIRI for a domain of size $1500 \mathrm{~km} \times 1000 \mathrm{~km}$ centered on the Cape Verde islands. The shadings refer to different cloud types derived with the cloud classification algorithm of the NWC-SAF v2016.

analysis) were roughly 50 to $130 \mathrm{~nm}$. The low value determined for $\kappa$ is in line with the fact that sodium chloride from sea salt was below the detection limit in the size-segregated chemical analysis for particles in this size range (Fig. 11), while insoluble EC and WSOM made up $30 \%$ of the main constituents at CVAO on average.

A thorough statistical analysis of $N_{\mathrm{CCN}}$ and particle hygroscopicity concerning different aerosol types is reported in Gong et al. (2020a). Figure 10a shows the median of marinetype PNSDs for cloud-free conditions and cloud events at CVAO and Mt. Verde. Figure 10b shows the scatter plot of $N_{\mathrm{CCN}}$ at CVAO versus those on Mt. Verde. For cloud-free conditions, all data points are close to the $1: 1$ line, indicating that $N_{\mathrm{CCN}}$ is similar at the CVAO and Mt. Verde. However, during cloud events, larger particles, mainly accumulationand coarse-mode particles, were activated to cloud droplets and were consequently removed by the inlet. Therefore, during these times, $N_{\mathrm{CCN}}$ at the CVAO was larger than the respective values measured on Mt. Verde. Altogether, these measurements suggested that, for cloud-free conditions, the aerosol particles measured at ground level (CVAO) represent the aerosol particles at the cloud level (Mt. Verde).

\subsubsection{Chemical composition of aerosol particles and cloud water}

Between 2 and 9 October, size-resolved aerosol particles at the CVAO and Mt. Verde were collected simultaneously. The relative contribution of their main chemical constituents (inorganic ions, water-soluble organic matter (WSOM), and elemental carbon) at both sites is shown in Fig. 11. Sulfate, ammonium and WSOM dominated the submicron particles, and the chemical composition aligned well with the $\kappa$ value from the hygroscopicity measurements (Gong et al., 2020a). The supermicron particles were mainly composed of sodium and chloride at both stations. These findings agree well with previous studies at the CVAO (Fomba et al., 2014; van Pinxteren et al., 2017). From the chemical composition no indication for anthropogenic influences was found as concentrations of elemental carbon and submicron potassium were low (see Table S5). However, according to the dust concentrations (Table 2) and the air mass origins (Fig. S1), as well as the PNSD (Gong et al., 2020a), the air masses during this period experienced low dust influences that were not visible from the main chemical constituents studied here. 

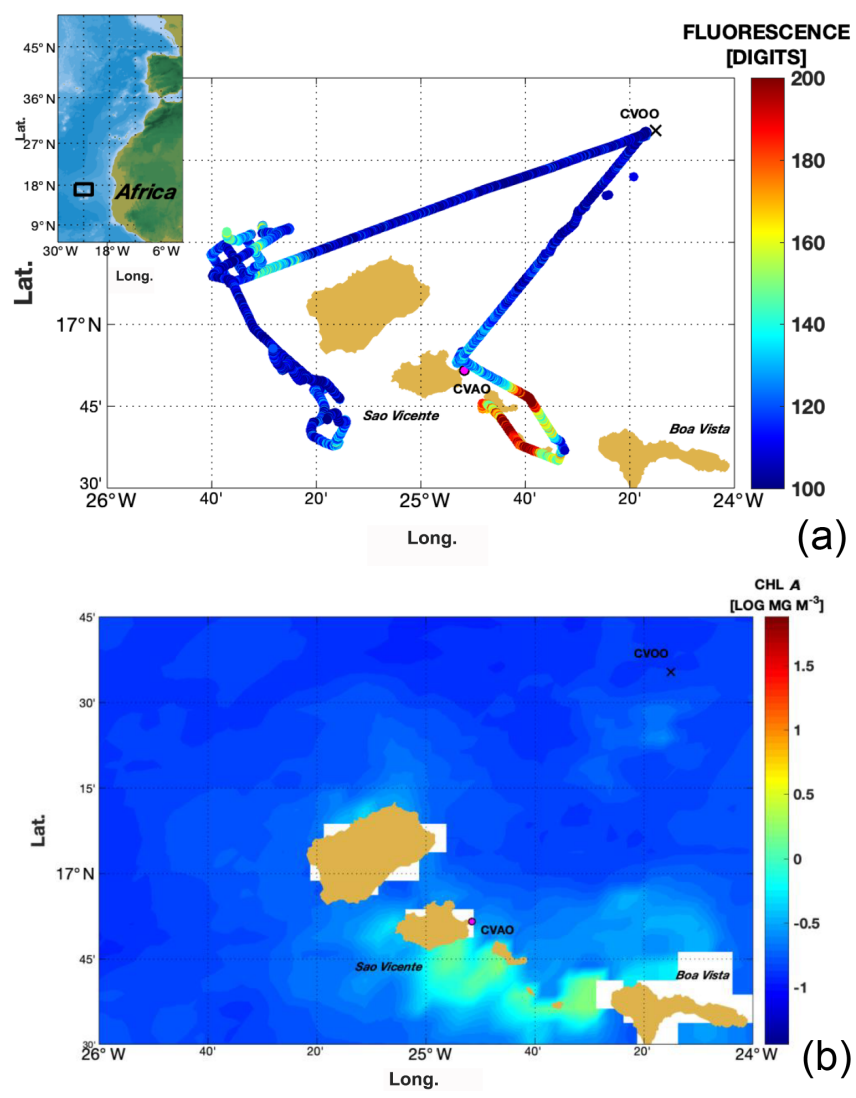

Figure 7. (a) The mission track of an SV2 wave glider as colorcoded fluorescence data derived from a Wet LABS FLNTURT sensor installed on the vehicle (data in arbitrary units) (b). Chlorophyll $a$ surface ocean concentrations derived from the MODIS Terra satellite (mean concentration for October 2017). Please note that logarithmic values are shown.

These findings warrant more detailed chemical investigations (like size-resolved dust measurements), a distinguishing between mass-based and number-based analysis, and detailed source investigations that are currently ongoing. The absolute concentrations of the aerosol constituents were lower at Mt. Verde compared to the CVAO site (Table S5); they were reduced by factor of 7 (supermicron particle) and by a factor of 4 (submicron particles). This decrease in the aerosol mass concentrations and the differences in chemical composition between the ground-based aerosol particles and the ones at Mt. Verde could be due to cloud effects as described in the previous section. Different types of clouds consistently formed and disappeared during the sampling period of the aerosol particles at Mt. Verde (more details about the frequency of the cloud events are available in the Supplement and in Gong et al., 2020a) and potentially affected the aerosol chemical composition. These effects will be more thoroughly examined in further analysis.

A first insight into the cloud water composition of a connected cloud water sampling event from 5-6 October is pre-
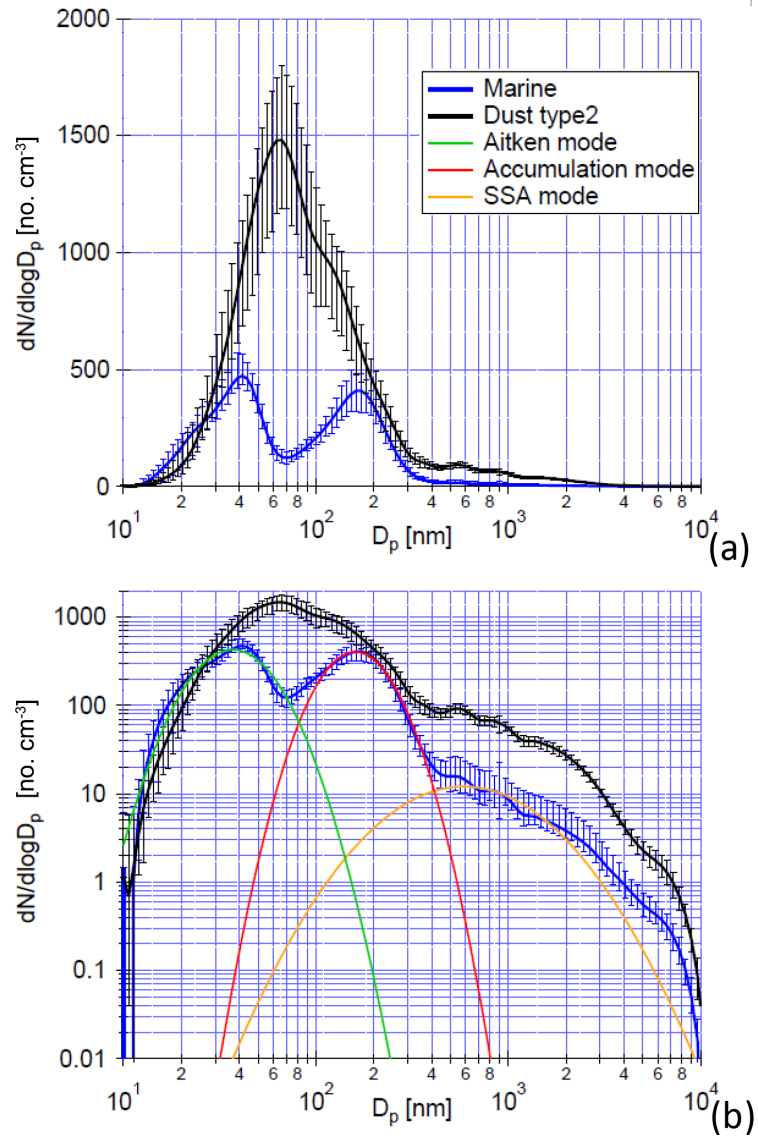

Figure 8. (a) The median of PNSDs of marine type (blue) and dust type (black), with a linear and (b) logarithmic scaling on the $y$ axis, measured from 21 September 03:30:00 to 21 September 20:00:00 (UTC) and from 28 September 09:30:00 to 30 September 18:30:00 (UTC). Panel (b) includes the aerosol size modes that fit the method also used in Modini et al., 2015. The error bar indicates the range between the 25 th and 75 th percentiles. This figure was adapted from Fig. 5 in Gong et al. (2020a).

sented in Fig. 12. Sea salt, sulfate and nitrate compounds dominated the chemical composition, making up more than $90 \%$ of the mass of the investigated chemical constituents. These compounds were also observed in the coarse fraction of the aerosol particles, suggesting that the coarse-mode particles served as efficient $\mathrm{CCN}$ and were efficiently transferred to the cloud water. To emphasize, these chemical analyses are based on mass, but the control of the cloud droplet number concentration comes from $\mathrm{CCN}$ number concentrations, including all particles with sizes roughly above $100 \mathrm{~nm}$. As larger particles contribute more to the total mass, chemical bulk measurements give no information about a direct influence of sea spray particles on cloud droplet concentrations, but they can show that the chemical composition is consistent with an (expected) oceanic influence on cloud water. No strong variations were found for the main cloud water constituents over the sampling period reported here. However, 


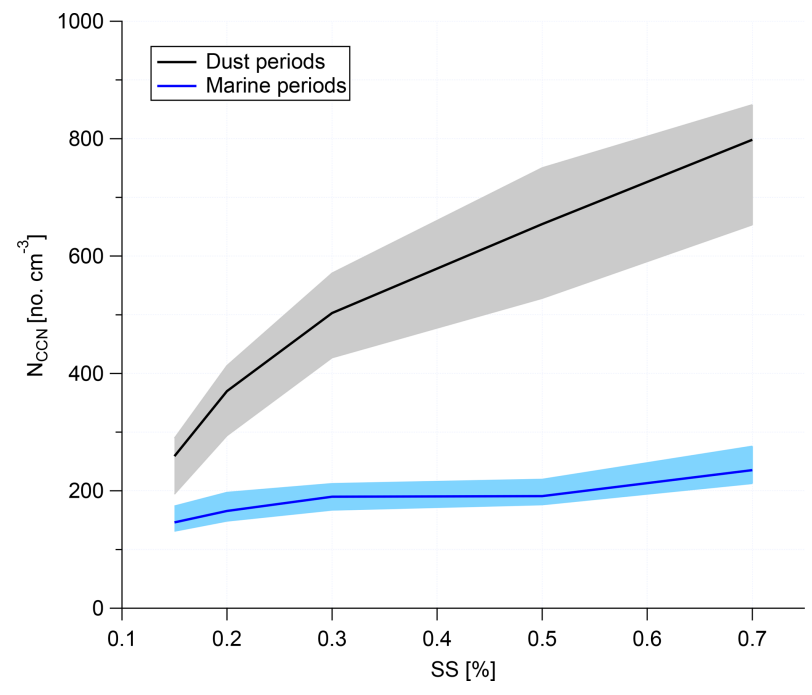

Figure 9. $N_{\mathrm{CCN}}$ as a function of supersaturation during dust (black line) and marine (blue line) periods. The shading shows the 25 th to 75 th percentiles.
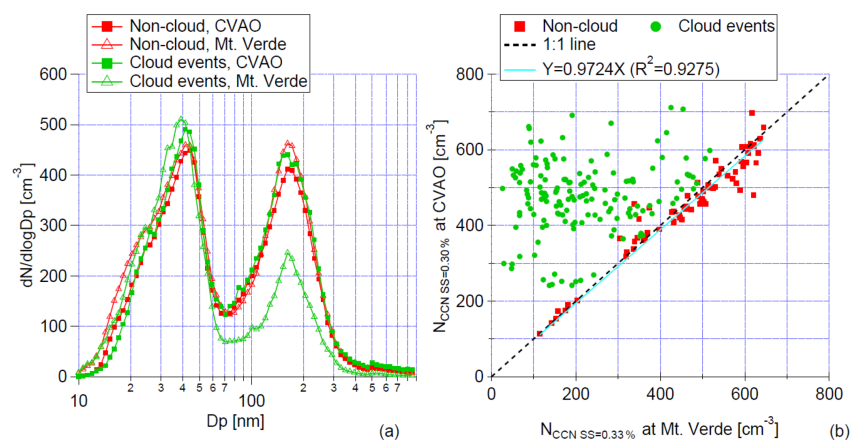

Figure 10. (a) The median of PNSDs for marine-type particles during cloud events and non-cloud events at CVAO and MV; (b) scatter plots of $N_{\mathrm{CCN}}$ at CVAO against those at $\mathrm{MV}$ at a supersaturation of $\sim 0.30 \%$. Slope and $R^{2}$ are given. This figure was adapted from Fig. 9 in Gong et al. (2020a).

the WSOM contributed with a maximal $10 \%$ to the cloud water composition and with higher contributions at the beginning and at the end of the sampling event, which warrants further analysis. The measured $\mathrm{pH}$ values of the cloud water samples ranged between 6.3 and 6.6 and agreed with previous literature data for marine clouds (Herrmann et al., 2015). In summary, cloud water chemical composition seemed to be dominated by coarse-mode aerosol particle composition, and the presence of inorganic marine tracers (sodium, methanesulfonic acid) shows that material from the ocean is transported to the atmosphere where it can become immersed in cloud droplets. More detailed investigations on the chemical composition, including a comparison of constituents from submicron aerosol particles and the SML with the cloud water composition, are planned.

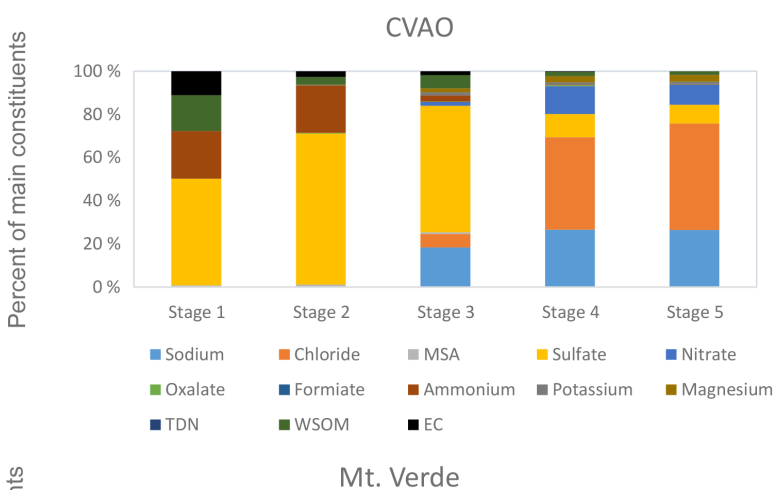

(a)

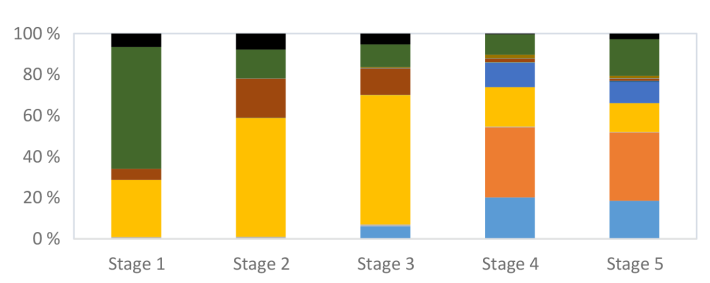

(b)

Figure 11. (a) Percentage aerosol composition at the CVAO (mean value of five blocks) and (b) at Mt. Verde (mean value of six blocks) between 2 and 9 October. Aerosol particles were samples in five different size stages from 0.05 to 0.14 (stage 1), 0.14 to 0.42 (stage 2), 0.42 to 1.2 (stage 3 ), 1.2 to 3.5 (stage 4 ) and 3.5 to $10 \mu \mathrm{m}$ (stage 5).

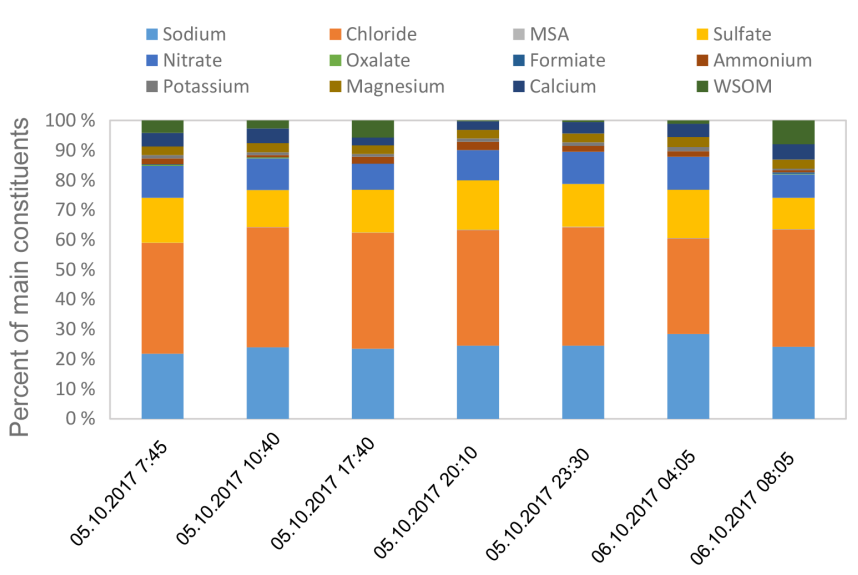

Figure 12. Cloud water composition for one connected sampling event between 5 October 7:45 (start; local time, UTC-1) and 6 October 08:45 (start; local time, UTC-1).

\subsection{Lipid biomarkers in aerosol particles}

Lipids from terrestrial sources such as plant waxes, soils and biomass burning have frequently been observed in the remote marine troposphere (Kawamura et al., 2003; Simoneit et al., 1977) and are common in marine deep-sea sediments. Within MarParCloud, marine-derived lipids were characterized in aerosol particles using lipid biomarkers in conjunction with compound-specific stable carbon isotopes. Bulk aerosol filters sampled at the CVAO and $\mathrm{PM}_{10}$ filters sam- 


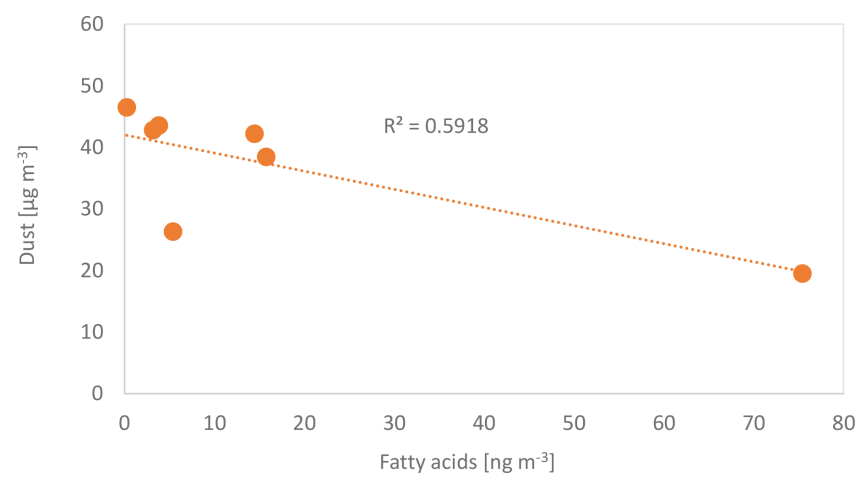

Figure 13. Straight-chain unsaturated fatty acid ( $\Sigma$; C12 to C33) concentrations on the $\mathrm{PM}_{10}$ aerosol particles versus atmospheric dust concentrations.

pled at Mt. Verde (not reported here) were extracted and the lipids were separated into functional groups for molecular and compound-specific carbon isotope analysis. The content of identifiable lipids was highly variable and ranged from 4 to $140 \mathrm{ng} \mathrm{m}^{3}$. These concentrations are in the typical range for marine aerosol particles (Mochida et al., 2002; Simoneit et al., 2004), but somewhat lower than previously reported for the tropical northeast Atlantic (Marty et al., 1979), and 1 to 2 orders of magnitude lower than reported from urban and terrestrial rural sites (Simoneit, 2004). They mainly comprised the homologue series of $n$-alkanoic acids, $n$-alkanols and $n$-alkanes. Among these the c16:0 acids and the c18:0 acids were by far the dominant compounds, each contributing $20 \%$ to $40 \%$ to the total observed lipids. This result aligns well with the findings of Cochran et al. (2016) from sea spray tank studies that connected the transfer of lipid-like compounds to their physicochemical properties such as solubility and surface activity. Among the terpenoids, dehydroabietic acid, 7-oxo-dehydroabietic acid and friedelin were present in some samples in remarkable amounts. Other terpenoid biomarkers, in particular phytosterols, were rarely detectable. The total identifiable lipid content was inversely related to dust concentration, as shown for the fatty acids (Fig. 13) with generally higher lipid concentrations in primary marine air masses. This is consistent with previous studies reporting low lipid yields in Saharan dust samples and higher yields in dust from the more vegetated savannahs and dry tropics (Simoneit et al., 1977). The first measurements of typical stable carbon isotope ratios of the lipid fractions were $(-28.1 \pm 2.5) \%$ for the fatty acids and $(-27.7 \pm 0.7) \%$ for the $n$-alkanes, suggesting a mixture of terrestrial C 3 and $\mathrm{C} 4$, as well as marine sources. In a separate contribution the lipid fraction of the aerosol particles in conjunction with its typical stable carbon isotope ratios will be further resolved.

\subsection{Trace gas measurements: dimethyl sulfide, ozone, (oxygenated) volatile organic compounds and nitrous acid}

Trace gases such as dimethyl sulfide (DMS), volatile organic compounds (VOCs) and oxygenated (O)VOCs were measured during the campaign, and the results are presented together with the meteorological data in Fig. 3. The atmospheric mixing ratios of DMS during this period ranged between 68 and $460 \mathrm{ppt}$ with a mean of $132 \pm 57 \mathrm{ppt}(1 \sigma)$. These levels were higher than the annual average mixing ratio for 2015 of $57 \pm 56 \mathrm{ppt}$; however, this may be due to seasonably high and variable DMS levels observed during summer and autumn at Cape Verde (observed mean mixing ratios were 86 and 107 ppt in September and October 2015). High DMS concentrations on 19-20 September occurred when air originated predominantly from the Mauritanian upwelling region (Fig. S1) and on 26 and 27 September. These elevated concentrations will be linked to the phytoplankton composition reported in Sect. 5.4.1 to elucidate associations, for example, between DMS and coccoliths (individual plates of calcium carbonate formed by coccolithophore phytoplankton) as observed by Marandino et al. (2008). Ethene showed similar variability as DMS, with coincident peaks ( $>300$ ppt DMS and $>40$ ppt ethene) on 20, 26 and 27 September, consistent with an oceanic source for ethene. Ethene can be emitted from phytoplankton (e.g., McKay et al., 1996), and therefore it is possible that it originated from the same biologically active regions as DMS. In the North Atlantic atmosphere, alkenes such as ethene emitted locally have been shown to exhibit diurnal behavior with a maximum at solar noon, suggesting photochemical production in seawater (Lewis et al., 2005). There was only weak evidence of diurnal behavior at Cape Verde (data not shown), possibly because of the very short atmospheric lifetime of ethene ( $8 \mathrm{~h}$ assuming $[\mathrm{OH}]=4 \times 10^{6}$ molecules $\mathrm{cm}^{-3}$; Vaughan et al., 2012) in this tropical environment, which would mask photochemical production. Mean acetone and methanol mixing ratios were $782 \mathrm{ppt}(566-1034 \mathrm{ppt})$ and $664 \mathrm{ppt}(551-780 \mathrm{ppt})$, respectively. These are similar to previous measurements at Cape Verde and in the remote Atlantic at this time of year (Lewis et al., 2005; Read et al., 2012). Methanol and acetone showed similar broad-scale features, indicating common sources. The highest monthly methanol and acetone concentrations have often been observed in September at Cape Verde, likely as a result of increased biogenic emissions from vegetation or plant matter decay in the Sahel region of Africa (Read et al., 2012). In addition to biogenic sources, (O)VOCs are anthropogenically produced from fossil fuels and solvent usage in addition to having a secondary source from the oxidation of precursors such as methane. Carpenter et al. (2010) showed that air masses originating from North America (determined via $10 \mathrm{~d}$ back trajectories) could impact (O) VOCs at the CVAO. 
The average ozone mixing ratio during the campaign was 28.7 ppb (19.4-37.8 ppb). Lower ozone concentrations on 27-28 September were associated with an influence from southern hemispheric air. Ozone showed daily photochemical loss, as expected in these very low- $\mathrm{NO}_{x}$ conditions, on most days with an average daily (from 09:00 to 17:00 UTC) loss of 4 ppbv. It was previously shown that the photochemical loss of $\mathrm{O}_{3}$ at Cape Verde and over the remote ocean is attributable to halogen oxides (29\% at Cape Verde) and ozone photolysis (54\%) (e.g., Read et al., 2008).

Finally, a series of continuous measurements of nitrous acid (HONO) was conducted, aiming to evaluate the possible contribution of marine surfaces to the production of HONO. The measurements indicated that HONO concentrations exhibited diurnal variations peaking at noontime. The concentrations during daytime (08:00 to 17:00 local time) and nighttime (17:30 to 07:00 local time) periods were around 20 and $5 \mathrm{ppt}$ on average, respectively. The fact that the observed data showed higher values during the day compared to the nighttime was quite surprising since HONO is expected to be photolyzed during the daytime. If confirmed, the measurements conducted here may indicate that there is an important HONO source in the area of interest. Altogether, for the trace gases, a variety of conditions were observed in this 3-week period with an influence from ocean-atmosphere exchange and also potential impacts of long-range transport.

\subsection{Organic matter and related compounds in seawater}

\subsubsection{Dissolved organic carbon and pigments}

Dissolved organic carbon (DOC) comprises a complex mixture of different compound groups and is diverse in its composition. For a first overview, DOC as a sum parameter was analyzed in all SML and bulk water samples (data in Table S4). The DOC concentration varied between 1.8 and $3.2 \mathrm{mg} \mathrm{L}^{1}$ in the SML and 0.9 and $2.8 \mathrm{mg} \mathrm{L}^{-1}$ in the bulk water; concentrations were in general agreement with previous studies at this location (e.g., van Pinxteren et al., 2017). A slight enrichment in the SML with an enrichment factor (EF) of $1.66( \pm 0.65)$ was found; i.e., SML concentrations contain roughly $70 \%$ more DOC that the corresponding bulk water. The concentrations of DOC in the bulk water together with the temporal evolution of biological indicators (pigments and the total bacterial cell numbers) and atmospheric dust concentrations are presented in Fig. 14.

Phytoplankton biomass expressed in chl $a$ was very low with $0.11 \mu \mathrm{g} \mathrm{L}^{-1}$ at the beginning of the campaign. Throughout the campaign two slight increases in biomass occurred but were always followed by a biomass depression. The biomass increase occurred towards the end of the study, when pre-bloom conditions were reached with values up to $0.6 \mu \mathrm{g} \mathrm{L}^{-1}$. These are above the typical chl $a$ concentration in this area. In contrast, the abundance of chlorophyll degradation products such as pheophorbide $a$ and pheophy-

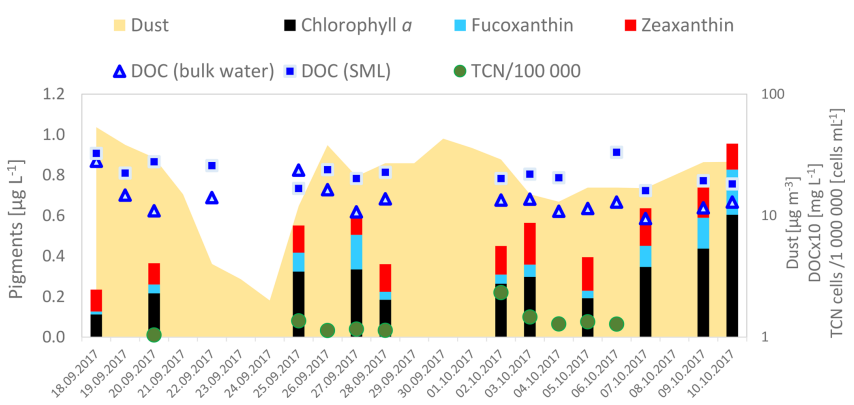

Figure 14. Temporal evolution of DOC concentrations in the bulk water samples along the campaign together with the main pigment (chl $a$, zeaxanthin and fucoxanthin) concentrations and total cell numbers measured in the bulk water and dust concentrations in the atmosphere (yellow background area).

thin $a$ decreased over time. The low concentrations of the chlorophyll degradation products suggested that only moderate grazing took place, and the pigment-containing organisms were fresh and in a healthy state. The most prominent pigment throughout the campaign was zeaxanthin, suggesting cyanobacteria as the dominant group in this region. This is in good agreement with the generally low biomass in the waters of the Cape Verde region and in line with previous studies reporting the dominance of cyanobacteria during the spring and summer seasons (Franklin et al., 2009; Hepach et al., 2014; Zindler et al., 2012). However, once the biomass increased, cyanobacteria were repressed by diatoms as indicated by the relative increase in fucoxanthin. The prymnesiophyte and haptophyte marker 19-hexanoyloxyfucoxanthin and the pelagophyte and haptophyte marker 19-butanoyloxyfucoxanthin were present and also increased when cyanobacteria decreased. In contrast, dinoflagellates and chlorophytes were background communities as indicated by their respective markers peridinin and chlorophyll $b$. Still, chlorophytes were much more abundant than dinoflagellates. In summary, the pigment composition indicated the presence of cyanobacteria, haptophytes and diatoms with a change in dominating taxa (from cyanobacteria to diatoms). The increasing concentration of chl $a$ and fucoxanthin implied that a bloom started to develop within the campaign dominated by diatoms. The increasing concentrations could also be related to changing water masses; however, since the oceanographic setting was relatively stable, the increasing chl $a$ concentrations suggest that a local bloom had developed, that might be related to the low but permanent presence of atmospheric dust input, which needs further verification. In the course of further data analysis of the campaign, the phytoplankton groups will be related to the abundance of, e.g., DMS (produced by haptophytes) or isoprene, which have been reported to be produced by diatoms or cyanobacteria (Bonsang et al., 2010), as well as to other VOCs. First analyses show that the DOC concentrations were not directly linked to the increasing chl $a$ con- 
centrations; however, their relation to single pigments, to the microbial abundance, to the background dust concentrations, and finally to wind speed and solar radiation will be further resolved to elucidate potential biological and meteorological controls on the concentration and enrichment of DOC.

\subsubsection{DOC concentrations: manual glass plate vs. MarParCat sampling}

For several dates, both SML sampling devices (glass plate and catamaran) were applied in parallel to compare the efficiency of different sampling approaches: manual glass plate and catamaran sampling (Fig. 15). As mentioned above both techniques used the same principle, i.e., the collection of the SML on a glass plate and its removal with a Teflon wiper. The deviation between the two techniques concerning DOC measurements was below $25 \%$ in 17 out of 26 comparisons and therefore within the range of variability of these measurements. However, in roughly $30 \%$ of all cases the concentration differences between the manual glass plate and catamaran were larger than $25 \%$. The discrepancy for the bulk water results could be related to the slightly different bulk water sampling depths using the MarParCat bulk water sampling system $(70 \mathrm{~cm})$ and the manual sampling with telescopic rods $(100 \mathrm{~cm})$. Although the upper meters of the ocean are assumed to be well mixed, recent studies indicate that small-scale variabilities can already be observed within the first $100 \mathrm{~cm}$ of the ocean (Robinson et al., 2019a).

The variations within the SML measurements could be due to the patchiness of the SML that has been tackled in previous studies (e.g., Mustaffa et al., 2017, 2018). Smallscale patchiness was recently reported as a common feature of the SML. The concentrations and compositions probably undergo more rapid changes due to high physical and biological fluctuations. Mustaffa et al. (2017) have recently shown that the enrichment of fluorescence dissolved matter (a part of DOC) showed short-timescale variability, changing by $6 \%$ within $10 \mathrm{~min}$ intervals. The processes leading to the enrichment of OM in the SML are probably much more complex than previously assumed (Mustaffa et al., 2018). In addition, the changes in DOC concentrations between the glass plate and the catamaran could result from the small variations of the sampling location as the catamaran was typically 15 to $30 \mathrm{~m}$ away from the boat where the manual glass plate sampling was carried out.

Given the highly complex matrix of seawater and especially the SML, the two devices applied were in quite good agreement considering DOC measurements. However, this is not necessarily the case for single parameters like specific organic compounds and INP concentrations. Low-concentrated constituents in particular might be more affected by small changes in the sampling procedure, and this remains to be evaluated for the various compound classes.

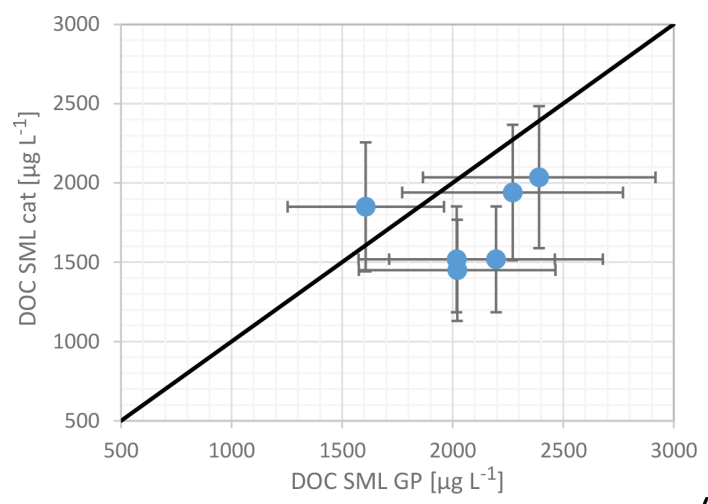

(a)

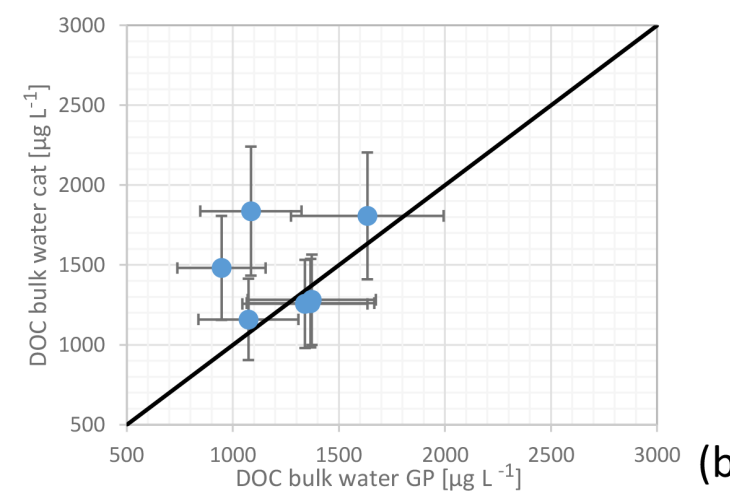

Figure 15. (a) Concentrations of DOC in the SML and (b) and in the bulk water sampled for paired glass plate (GP) and the MarParCat (cat) sampling events.

\subsubsection{Surfactants and lipids in seawater}

Due to their physicochemical properties, surfactants (SASs) are enriched in the SML relative to the bulk water and form surface films (Frka et al., 2009, 2012; Wurl et al., 2009). During the present campaign, the SASs in the dissolved fraction of the SML samples ranged from 0.037 to $0.125 \mathrm{mg}$ of Triton-X-100 equivalent per liter with a mean of $0.073 \pm 0.031 \mathrm{mg}$ of Triton-X-100 equivalent per liter $(n=$ 7 ). For bulk water, the dissolved SASs ranged from 0.020 to $0.068 \mathrm{mg}$ of Triton-X-100 equivalent per liter (mean $0.051 \pm$ $0.019 \mathrm{mg}$ of Triton-X-100 equivalent per liter, $n=12$ ). The SAS enrichment showed EFs from 1.01 to 3.12 (mean EF = $1.76 \pm 0.74$ ) (Fig. 16) and was slightly higher than that for the DOC (mean EF $=1.66 \pm 0.65$ ), indicating some higher surfactant activity of the overall DOM in the SML with respect to the bulk DOM. An accumulation of the total dissolved lipids (DLs) in the SML was observed as well (mean $\mathrm{EF}=1.27 \pm 0.12$ ). Significant correlation was observed between the SAS and DL concentrations in the SML $(r=$ $0.845, n=7, p<0.05)$, while no correlation was detected for the bulk water samples. Total DL concentrations ranged from 82.7 to $148 \mu \mathrm{g} \mathrm{L}^{-1}$ (mean $108 \pm 20.6 \mu \mathrm{g} \mathrm{L}^{-1}, n=8$ ) and from 66.5 to $156 \mu \mathrm{g} \mathrm{L}^{-1}$ (mean $96.9 \pm 21.7 \mu \mathrm{g} \mathrm{L}^{-1}, n=17$ ) 


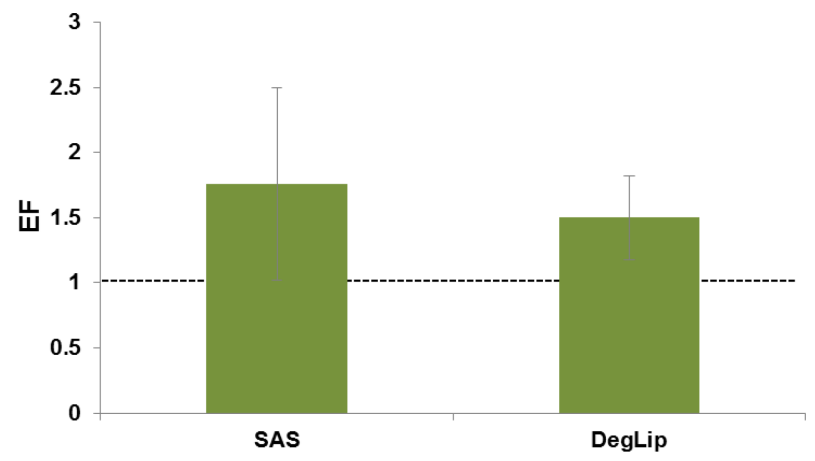

Figure 16. Average enrichment (EF) of surfactants (SASs) and dissolved lipid classes indicating organic matter degradation (DegLip).

in the SML and the bulk water, respectively. In comparison to the bulk water, the SML samples were enriched with lipid degradation products, e.g., free fatty acids and long-chain alcohols (DegLip; mean $\mathrm{EF}=1.50 \pm 0.32$ ) (Fig. 16), pointing to their accumulation from the bulk and/or enhanced OM degradation within the SML. DegLips are strong surfaceactive compounds (known as dry surfactants), which play an important role in surface film establishment (Garrett, 1965). The overall surfactant activity of the SML is the result of the competitive adsorption of highly surface-active lipids and other less surface-active macromolecular compounds (polysaccharides, proteins, humic material) (Ćosović and Vojvodić, 1998) dominantly present in seawater. The presence of even low amounts of lipids results in their significant contribution to the overall surface-active character of the SML complex organic mixture (Frka et al., 2012). The observed biotic and/or abiotic lipid degradation processes within the SML will be further resolved by combining surfactant and lipid results with detailed pigment characterization and microbial measurements. The same OM classes of the ambient aerosol particles will be investigated and compared with the seawater results. This will help to tackle the question of to what extent the seawater exhibits a source of OM on aerosol particles and which important aerosol precursors are formed or converted in surface films.

\subsection{Seawater untargeted metabolomics}

For a further OM characterization of SML and bulk seawater, an ambient MS-based metabolomics method using direct analysis in real-time quadrupole time-of-flight mass spectrometry (DART-QTOF-MS) coupled to multivariate statistical analysis was designed (Zabalegui et al., 2019). A strength of a DART ionization source is that it is less affected by high salt levels than an electrospray ionization source (Kaylor et al., 2014), allowing for the analysis of seawater samples without observing salt deposition at the mass spectrometer inlet, or having additional limitations such as low ionization efficiency due to ion suppression (Tang et al., 2004). Based on these advantages, paired SML-bulk water samples were analyzed without the need for desalinization by means of a transmission-mode (TM) DART-QTOF-MS-based analytical method that was optimized to detect lipophilic compounds (Zabalegui et al., 2019). An untargeted metabolomics approach, referred to as seaomics, was implemented for sample analysis. SML samples were successfully discriminated from ULW samples based on a panel of ionic species extracted using chemometric tools. The coupling of the DART ion source to high-resolution instrumentation allowed for generating elemental formulae for unknown species, and tandem MS capability contributed to the identification process. Tentative identification of discriminant species and the analysis of relative compound abundance changes among sample classes (SML and bulk water) suggested that fatty alcohols, halogenated compounds and oxygenated boron-containing organic compounds may be involved in water-air transfer processes and in photochemical reactions at the water-air interface of the ocean (Zabalegui et al., 2019). These identifications (e.g., fatty alcohols) agree well with the abundance of lipids in the respective samples. In this context, TM-DARTHR-MS appears to be an attractive strategy to investigate the seawater OM composition without requiring a desalinization step.

\subsection{Ocean surface mercury associated with organic matter}

Several elements are known to accumulate in the SML. In the case of $\mathrm{Hg}$, the air-sea exchange plays an important role in its global biogeochemical cycle, and hence the processing of $\mathrm{Hg}$ in the SML is of particular interest. Once deposited from the atmosphere to the ocean surface via dry and wet deposition, divalent mercury $\left(\mathrm{Hg}^{\mathrm{II}}\right)$ can be transported to the deeper ocean by absorbing on sinking OM particles, followed by methylation. On the other hand, $\mathrm{Hg}^{\mathrm{II}}$ complexed by DOM in the ocean surface can be photoreduced to $\mathrm{Hg}^{0}$, which evades into the gas phase. In both processes, OM, dissolved or particulate, is the dominant factor influencing the complexation and adsorption of $\mathrm{Hg}$. To explore the $\mathrm{Hg}$ behavior with $\mathrm{OM}$, the concentrations of total and dissolved $\mathrm{Hg}$ as well as methylmercury $(\mathrm{MeHg})$ were determined in the SML and in the bulk water using US EPA methods 1631 and 1630, as described in Li et al. (2018). Figure 17 shows the concentrations of $\mathrm{Hg}$ and $\mathrm{MeHg}$ associated with DOC and POC in the SML and bulk water. The total Hg concentrations were 3.6 and $4.6 \mathrm{ng} \mathrm{L}^{-1}$ in the SML but 3.1 and $1.3 \mathrm{ng} \mathrm{L}^{-1}$ in the bulk water on 26 and 27 September, respectively, which were significantly enriched compared to data reported for the deep North Atlantic $\left(0.18 \pm 0.06 \mathrm{ng} \mathrm{L}^{-1}\right)$ (Bowman et al., 2015). Atmospheric deposition and more $\mathrm{OM}$-adsorbing $\mathrm{Hg}$ are believed to result in high total $\mathrm{Hg}$ at the ocean surface. The dissolved $\mathrm{Hg}$ concentrations were enriched by 1.7 and 2.7 times in the SML relative to bulk water, consistent with the enrichments of DOC by a factor of 1.4 and 1.9 on 26 and 27 September, respectively. Particulate 


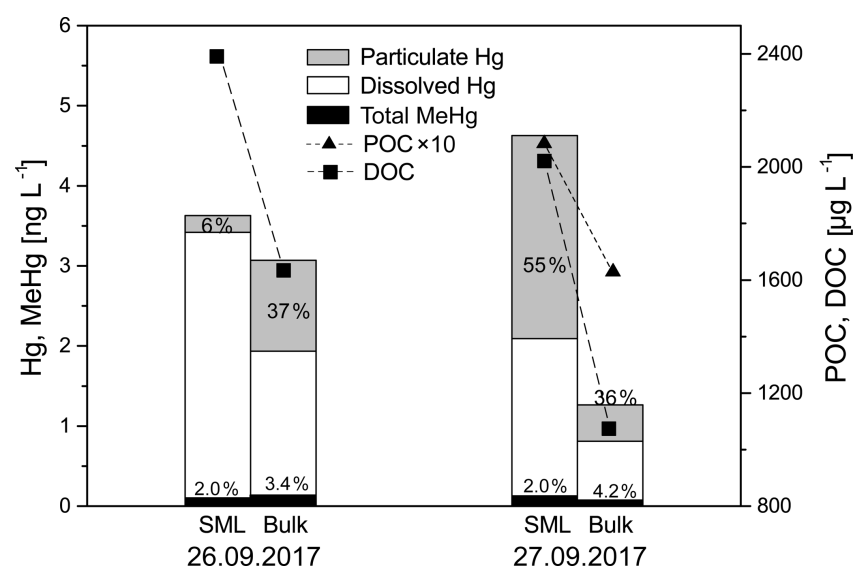

Figure 17. Concentrations of $\mathrm{Hg}, \mathrm{MeHg}$, DOC and $\mathrm{POC}$ in the sea surface microlayer (SML) and bulk water sampled on 26 and 27 September 2017.

$\mathrm{Hg}$ in the SML accounted for only $6 \%$ of the total Hg concentration on 26 September but $55 \%$ on 27 September, in contrast to their similar fractions of $\sim 35 \%$ in the bulk water on both days. According to the back trajectories (Fig. S1) a stronger contribution of African continental sources (e.g., dust) was observed on 27 September that might be linked to the higher concentrations of particulate $\mathrm{Hg}$ in the SML on this day. The water-particle partition coefficients $\left(\log K_{d}\right)$ for $\mathrm{Hg}$ in the SML $\left(6.8 \mathrm{~L} \mathrm{~kg}^{-1}\right)$ and bulk water $\left(7.0 \mathrm{~L} \mathrm{~kg}^{-1}\right)$ were similar regarding $\mathrm{POC}$ as the sorbent but one unit higher than the reported $\log \mathrm{K}_{\mathrm{d}}$ values in seawater $\left(4.9-6.1 \mathrm{~L} \mathrm{~kg}^{-1}\right)(\mathrm{Ba}-$ trakova et al., 2014). MeHg made up lower proportions of the total $\mathrm{Hg}$ concentrations in the SML (2.0\%) than bulk water $(3.4 \%$ and $4.2 \%)$, probably due to the photodegradation or evaporation of $\mathrm{MeHg}$ at the surface water (Blum et al., 2013). From the first results, it seems that the SML is the major compartment where $\mathrm{Hg}$ associated with $\mathrm{OM}$ is enriched, while $\mathrm{MeHg}$ is more likely concentrated in deeper water. The limited data underline the importance of the SML in Hg enrichment dependent on $\mathrm{OM}$, which needs further studies to understand the air-sea exchange of $\mathrm{Hg}$.

\subsection{Ocean-atmosphere transfer of organic matter and related compounds}

\subsubsection{Dissolved organic matter classes}

To investigate the complexity of dissolved organic matter (DOM) compound groups, liquid chromatography, organic carbon detection, organic nitrogen detection and UV absorbance detection (LC-OCD-OND-UVD; Huber et al., 2011; more details in the Supplement) were combined and applied to identify five different DOM classes. These classes include (i) biopolymers that are likely hydrophobic, high-molecular-weight ( $\gg 20000 \mathrm{~g} \mathrm{~mol}^{-1}$ ), largely non-UVabsorbing extracellular polymers; (ii) "humic substances" (with higher molecular weight at $\sim 1000 \mathrm{~g} \mathrm{~mol}^{-1}$, UVabsorbing); (iii) "building blocks" that are lower-molecularweight (300-500 $\mathrm{g} \mathrm{mol}^{-1}$ ), UV-absorbing humics; (iv) lowmolecular-weight "neutrals" $\left(350 \mathrm{~g} \mathrm{~mol}^{-1}\right.$, hydrophilic or amphophilic, non-UV-absorbing); and (v) low-molecularweight acids $\left(350 \mathrm{~g} \mathrm{~mol}^{-1}\right)$. These measurements were performed from a first set of samples from all the ambient marine compartments. That comprised three SML samples and the respective bulk water, three aerosol particle filter samples $\left(\mathrm{PM}_{10}\right)$ from the CVAO and two from Mt. Verde, and finally four cloud water samples collected during the campaign. The DOM concentrations were derived from the sum of the individual compound groups $\left(\mu \mathrm{gL}^{-1}\right)$, and the EFs for DOM varied from 0.83 to 1.46 , which agrees very well with the DOC measurements described in Sect. 5.4.1. A clear compound group that drove this change has not been identified so far. Figure 18 shows the relative composition of the measured DOM groups in the distinct marine compartments as an average of the single measurements (concentrations are listed in Table S6). In the SML and in the bulk water, the low-molecular-weight neutral (LMWN) compounds generally dominated the overall DOM pool (37\% to $51 \%$ ). Humic-like substances, building blocks and biopolymeric substances contributed $22 \%$ to $32 \%, 16 \%$ to $23 \%$ and $6 \%$ to $12 \%$, respectively. Interestingly, low-molecularweight acids (LMWAs) were predominantly observed in the SML ( $2 \%$ to $8 \%$ ) with only one bulk water time point showing any traces of LMWA. This finding agreed well with the presence of free amino acids (FAAs) in the SML; e.g., the sample with the highest LMWA concentration showed the highest FAA concentration (more details in Triesch et al., 2020). Further interconnections between the DOM fractions and single organic markers and groups (e.g., sugars, lipids and surfactants; see Sect. 5.4.3) are subject to ongoing work. In contrast, aerosol particles were dominated by building blocks $(46 \%$ to $66 \%)$ and LMWN (34\% to $51 \%)$ compound groups, with a minor contribution of LMWA $(>6 \%)$. Interestingly, higher-molecular-weight compounds of humiclike substances and biopolymers were not observed. Cloud water samples had a variable contribution of substances in the DOM pool, with humic substances and building blocks generally dominating (27\% to $63 \%$ and $16 \%$ to $29 \%$, respectively) and lower contributions of biopolymers ( $2 \%$ to $4 \%$ ) and LMW acids and neutrals (1\% to $20 \%$ and $18 \%$ to $34 \%)$ observed. The first measurements indicate that the composition of the cloud waters is more consistent with the SML and bulk water and different from the aerosol particle's composition. This observation suggests a two-stage process whereby selective aerosolization mobilizes lower-molecularweight humics (building blocks) into the aerosol particle phase, which may aggregate in cloud waters to form larger humic substances. These preliminary observations need to be further studied with a larger set of samples and could relate to different solubilities of the diverse OM groups in water, the interaction between DOM and particulate OM (POM), 


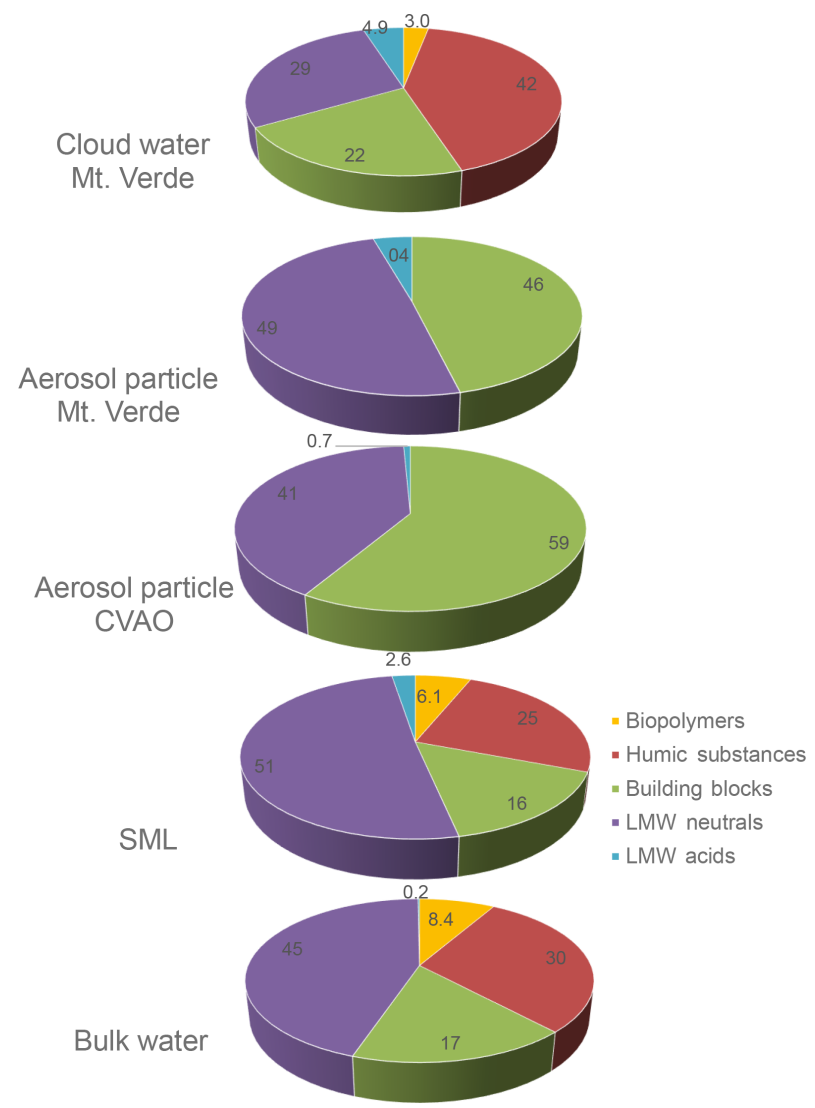

Figure 18. DOM classes measured in all compartments. The data represent mean values of three SML samples and the respective bulk water, three aerosol particle samples $\left(\mathrm{PM}_{10}\right)$ from the CVAO and two aerosol samples $\left(\mathrm{PM}_{10}\right)$ from Mt. Verde, and four cloud water samples, all collected during 26-27 September as well as 1-2 and 8-9 October 2017.

including TEP formation, or an indication of the different OM sources and transfer pathways. In addition, the chemical conditions, like $\mathrm{pH}$ value or redox, could preferentially preserve or mobilize DOM fractions within the different types of marine waters. In summary, all investigated compartments showed a dominance of LMW neutrals and building blocks, which suggests a link between the seawater, aerosol particles and cloud water at this location and possible transfer processes. Furthermore, the presence of humic-like substances, biopolymers and partly LMWA in the seawater and cloud water, but not in the aerosol particles, suggests an additional source or formation pathway of these compounds. For a comprehensive picture, however, additional samples need to be analyzed and interpreted in future work. It is worth noting that the results presented here are the first for such a diverse set of marine samples and demonstrate the potential usefulness of identifying changes in the flux of DOM between marine compartments.

A more comprehensive set of samples was analyzed for FAAs on a molecular level as important organic-nitrogen- containing compounds (Triesch et al., 2020). The FAAs, likely resulting from the ocean, were strongly enriched in submicron aerosol particles $\left(\mathrm{EF}_{\mathrm{aer}(\mathrm{FAA})}=10^{2}-10^{4}\right)$ and to a lesser extent enriched in supermicron aerosol particles $\left(\mathrm{EF}_{\mathrm{aer}(\mathrm{FAA})}=10^{1}\right)$. The cloud water contained the FAAs in significantly higher concentrations compared to their respective seawater concentrations, and they were enriched by a factor of $4 \times 10^{3}$ compared to the SML. These high concentrations cannot currently be explained, and possible sources such as the biogenic formation or enzymatic degradation of proteins, selective enrichment processes, or $\mathrm{pH}$-dependent chemical reactions are subject to future work. The presence of high concentrations of FAAs in submicron aerosol particles and in cloud water, together with the presence of inorganic marine tracers (sodium, methane-sulfonic acid), points to an influence of oceanic sources on the local clouds (Triesch et al., 2020).

\subsubsection{Transparent exopolymer particles: field and tank measurements}

As part of the OM pool, gel particles, such as positive buoyant transparent exopolymer particles (TEPs), formed by the aggregation of precursor material released by plankton and bacteria accumulate at the sea surface. The coastal water in Cape Verde was shown to be oligotrophic with low chl $a$ abundance during the campaign (more details in Sect. 4.2.1). Based on previous work (Wurl et al., 2011) it is expected that surfactant enrichment, which is closely linked to TEP enrichment, in the SML would be higher in oligotrophic waters but have a lower absolute concentration. This complements the findings achieved here, which showed low TEP abundance in these nearshore waters; the abundance in the bulk water ranged from 37 to $144 \mu \mathrm{g}$ of xanthan gum equivalent per liter and 99 to $337 \mu \mathrm{g}$ of xanthan gum equivalent per liter in the SML. However, while the SML layer was relatively thin $(\sim 125 \mu \mathrm{m})$ there was positive enrichment of TEPs in the SML, with an average EF of $2.0 \pm 0.8$ (Fig. 19a). The enrichment factor for TEPs was furthermore very similar to surfactant enrichment (Sect. 5.4.3).

In addition to the field samples, a tank experiment was run simultaneously using the same source of water. Breaking waves were produced via a waterfall system (details in the Supplement), and samples were collected from the SML and bulk water after a wave simulation time of $3 \mathrm{~h}$. TEP abundance in the tank experiment matched the field samples at the beginning but quickly increased to $1670 \mu \mathrm{g}$ of xanthan gum equivalent per liter in the SML, with an EF of 13.2 after the first day of bubbling (Fig. 19b). The enrichment of TEPs in the SML during the tank experiment had a cyclical increase and decrease pattern. Interestingly, in the field samples, even on days with moderate wind speeds $\left(>5 \mathrm{~m} \mathrm{~s}^{-1}\right)$ and the occasional presence of white caps, TEP abundance or enrichment did not increase, but it did increase substantially due to the waves in the tank experiment. This suggests 


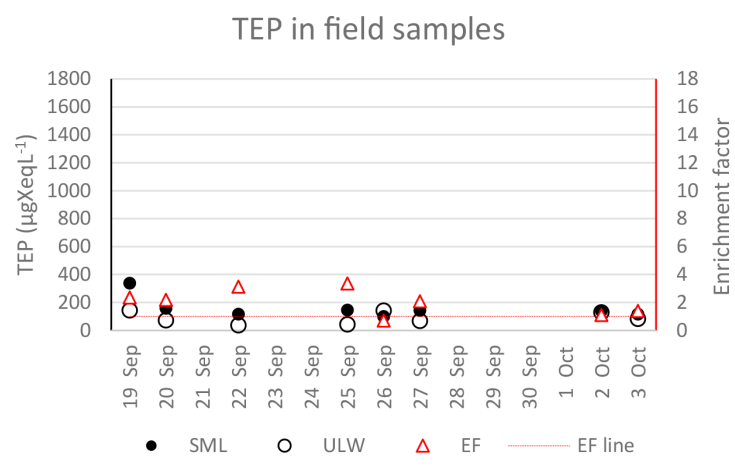

(a)

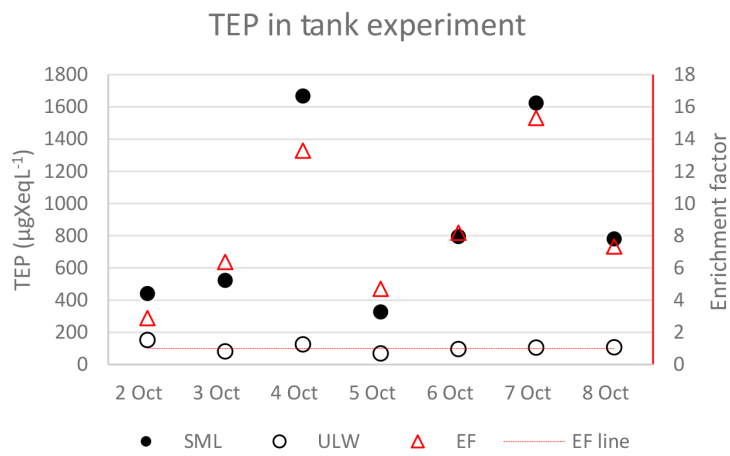

Figure 19. (a) Total TEP abundance in the SML and the bulk water as well as the enrichment factor (SML/ULW) of TEPs for field samples taken in the nearshore water of Cape Verde, (b) together with a tank experiment including $>3 \mathrm{~h}$ bubbling of water collected from nearshore Cape Verde.

that the simulated waves are very effective in enriching TEPs in the SML, and TEPs were more prone to transport or formation by bubbling than by other physical forces, confirming bubble-induced TEP enrichment in recent artificial setups (Robinson et al., 2019b). Besides the detailed investigations of TEPs in seawater, first analyses show a clear abundance of TEPs in the aerosol particles and in cloud water. Interestingly, a major part of TEPs seems to be located in the submicron aerosol particles (Fig. 20). Submicron aerosol particles represent the longest-living aerosol particle fraction; they have a high probability to reach cloud level and to contribute to cloud formation and the occurrence of TEPs in cloud water, which strongly underlines the possible vertical transport of these ocean-derived compounds.

\subsubsection{Bacterial abundance in distinct marine samples: field and tank measurements}

The OM concentration and composition are closely linked with biological and especially microbial processes within the water column. Throughout the sampling period, the temporal variability of bacterial abundance in the SML and bulk water was studied (data listed in Table S4). Mean absolute cell numbers were $1.3 \pm 0.2 \times 10^{6}$ cells $\mathrm{mL}^{-1}$ and $1.2 \pm$

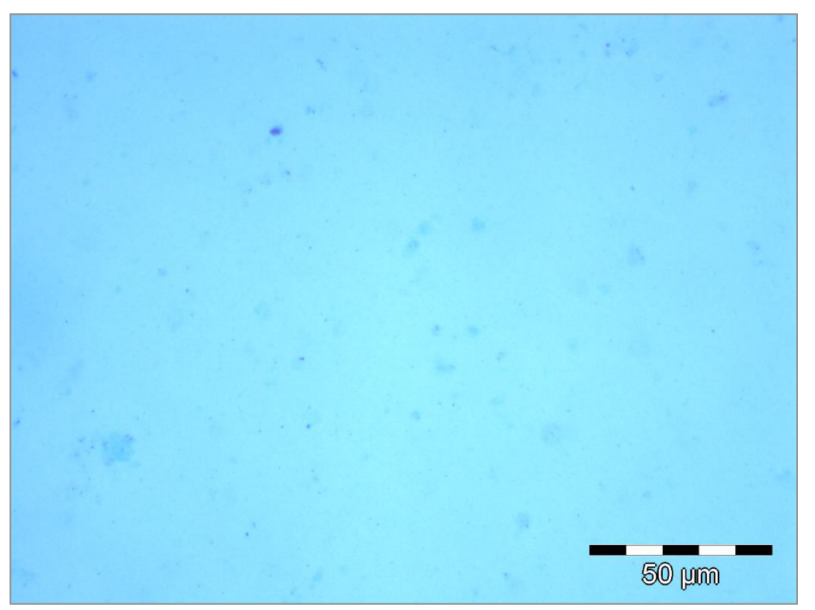

Figure 20. Microscopy image of TEPs in TSP aerosol particles sampled at the CVAO between 29 and 30 September with a flow rate of $8 \mathrm{~L} \mathrm{~min}^{-1}$.

$0.1 \times 10^{6}$ cells $\mathrm{mL}^{-1}$ for SML and bulk water, respectively (Fig. 21a; all data listed in Table S4). While comparable SML data are lacking for this oceanic province, our data are in range with previous reports for surface water of subtropical regions (Zäncker et al., 2018). A strong day-to-day variability of absolute cell numbers was partly observed (e.g., the decline between 25 and 26 September), but all these changes were found in both the SML and bulk water (Fig. 21a). This indicates that the upper water column of the investigated area experienced strong changes, e.g., by inflow of different water masses and/or altered meteorological forcing. As for the absolute abundance, the enrichment of bacterial cells in the SML was also changing throughout the sampling period, with EFs ranging from 0.88 to 1.21 (Fig. 21b). A detailed investigation of physical factors (e.g., wind speed, solar radiation) driving $\mathrm{OM}$ concentration and bacterial abundance in the SML and bulk water will be performed to explain the short-term variability observed. Further ongoing investigations aim to determine the bacterial community composition by $16 \mathrm{~S}$ sequencing approaches. The resulting comparison of water and aerosol particle samples will help to better understand the specificity of the respective communities and to gain insights into the metabolic potential of abundant bacterial taxa in aerosol particles. During the tank experiment, cell numbers ranged between 0.6 and $2.0 \times 10^{6}$ cells mL ${ }^{-1}$ (Fig. 21c); the only exception was observed on 3 October, when cell numbers in the SML reached $4.9 \times 10^{6}$ cells $\mathrm{mL}^{-1}$. Both in the SML and bulk water, bacterial cell numbers decreased during the experiment, which may be attributed to limiting substrate supply in the closed system. Interestingly, SML cell numbers always exceeded those from the bulk water (Fig. 21d), although the SML was permanently disturbed by bursting bubbles throughout the entire experiment. This seems to be in line with the high TEP concentrations observed for the SML in the tank (Sect. 5.7.2). A recent study 
showed that bubbles are very effective transport vectors for bacteria into the SML, even within minutes after disruption (Robinson et al., 2019a). The decline of SML bacterial cell numbers (both absolute and relative) during the experiment may be partly caused by permanent bacterial export into the air due to bubble bursting. Although this conclusion remains speculative as cell abundances of air samples are not available for our study, previous studies have shown that the aerosolization of cells may be quite substantial (Rastelli et al., 2017). Bacterial abundance in cloud water samples taken at Mt. Verde during the MarParCloud campaign ranged between 0.4 and $1.5 \times 10^{5}$ cells $\mathrm{mL}^{-1}$ (Fig. 21a). Although few samples are available, these numbers agree well with previous reports (e.g., Hu et al., 2018).

\subsubsection{Ice-nucleating particles}

The properties of ice-nucleating particles (INPs) in the SML and in bulk seawater (airborne in the marine boundary layer), as well as the contribution of sea spray aerosol particles to the INP population in clouds, were examined during the campaign. The numbers of INPs $\left(N_{\text {INP }}\right)$ at $-12,-15$ and $-18{ }^{\circ} \mathrm{C}$ in the $\mathrm{PM}_{10}$ samples from the CVAO varied from 0.000318 to $0.0232,0.00580$ to 0.0533 and 0.0279 to 0.100 per liter (for standard temperature and pressure), respectively. INP measurements in the ocean water showed that the enrichment and depletion of INPs in the SML compared to the bulk seawater occurred, and enrichment factors varied from 0.36 to 11.40 and 0.36 to 7.11 at -15 and $-20^{\circ} \mathrm{C}$, respectively (details

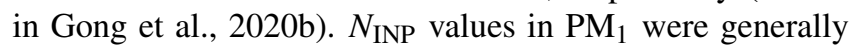
lower than those in $\mathrm{PM}_{10}$, and, furthermore, $N_{\mathrm{INP}}$ in $\mathrm{PM}_{1}$ at CVAO did not show elevated $N_{\text {INP }}$ at warm temperatures, in contrast to $N_{\text {INP }}$ in $\mathrm{PM}_{10}$. These elevated concentrations in $\mathrm{PM}_{10}$ decreased upon heating the samples, clearly pointing to a biogenic origin of these INPs. Therefore, ice-active particles in general and biologically active INPs in particular were mainly present in the supermicron particles, and particles in this size range are not suggested to undergo strong enrichment of OM during oceanic transfer via bubble bursting (Quinn et al., 2015, and references therein). $N_{\text {INP }}$ (per volume of water) of the cloud water was roughly similar to or slightly above that of the SML (Fig. 22), while concentrations of sea salt were clearly lower in cloud water compared to ocean water. Assuming sea salt and the INPs to be similarly distributed in both sea and cloud water (i.e., assuming that INPs would not be enriched or altered during the production of supermicron sea spray particles), $N_{\text {INP }}$ is at least 4 orders of magnitude higher than what would be expected if all airborne INPs originated from sea spray. These first measurements indicate that other sources besides the ocean, such as mineral dust or other long-range-transported particles, contributed to the local INP concentration (details in Gong et al., 2020b).

\subsection{The SML potential to form secondary organic aerosol particles}

To explore if marine air masses exhibit significant potential to form SOA, a Gothenburg potential aerosol mass reactor (Go : PAM) was used that relies on providing a highly oxidizing medium to reproduce atmospheric oxidation on timescales ranging from a day to several days in much shorter timescales (i.e., a few minutes). During the campaign, outdoor air and gases produced from a photochemical reactor were flowed through the Go: PAM (Watne et al., 2018) and exposed to high concentrations of $\mathrm{OH}$ radicals formed via the photolysis of ozone and subsequent reaction with water vapor (Zabalegui et al., 2019, and references therein). The aerosol particles produced at the outlet of the OFR were monitored by means of an SMPS, i.e., only size distribution and number concentration were monitored. A subset of the collected SML samples were investigated within the Go: PAM and showed that particles were formed when these samples were exposed to actinic irradiation. These particles most likely resulted from the reaction of ozone with gaseous products that were released from the SML as shown recently (Ciuraru et al., 2015), and the results obtained here are explained in more detail in a separate paper by Zabalegui et al. (2019). Zabalegui et al. (2019) also pointed out the clear need to have concentrated SML samples (achieved here by centrifugation of the authentic samples) as for prerequisite of aerosol formation, which points toward a specific "organicrich" chemistry. Outdoor air masses were also investigated for their secondary mass production potential. During the campaign, northeast wind dominated; i.e., predominantly clean marine air masses were collected. Those did not show any distinct diurnal difference for their secondary aerosol formation potential. However, a significant decrease in secondary organic mass was observed on 30 September, which will be analyzed in more detail.

\subsection{The way to advanced modeling}

\subsubsection{Modeling of cloud formation and vertical transfer of ocean-derived compounds}

Besides the assessment of cloud types (Sect. 4.1.4), modeling approaches are planned to be applied to simulate the occurrence and formation of clouds at the Mt. Verde site, including advection, wind, effective transport and vertical transport. This will allow us to model chemical multiphase processes under the given physical conditions. Furthermore, the potential vertical transfer of ocean-derived compounds to the cloud level will be modeled. To this end, the meteorological model data by the Consortium for Small-scale Modelling-Multiscale Chemistry Aerosol Transport Model (COSMO) (Baldauf et al., 2011) will be used to define a vertical meteorological data field. COSMO is a compressible and non-hydrostatic meteorological model and the cur- 
(a)

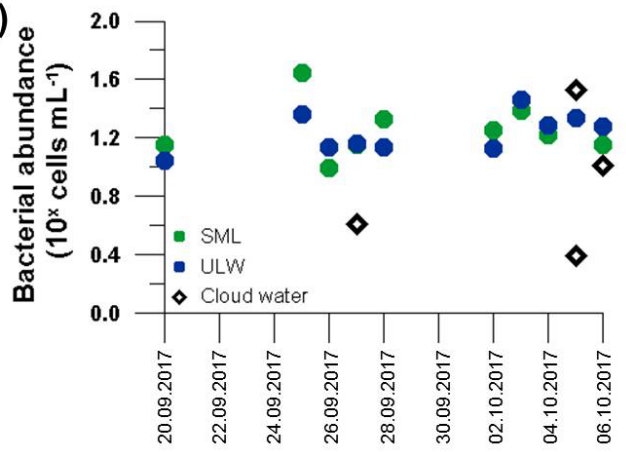

(c)

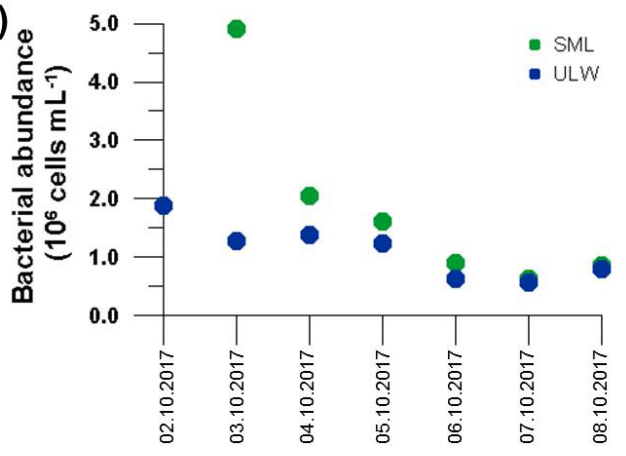

(b)

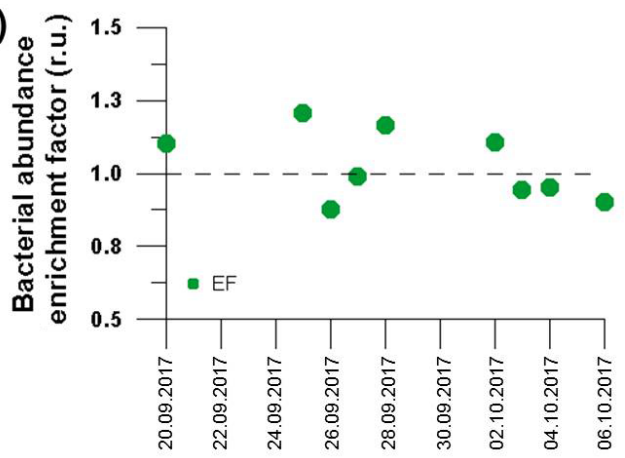

(d)

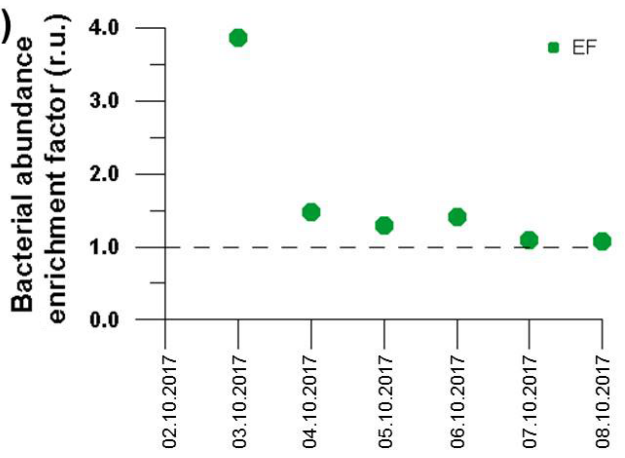

Figure 21. Bacterial abundance of SML and ULW from (a) field and (c) tank water samples as well as from cloud water samples (diamonds, a) taken during the campaign. Additionally, enrichment factors (i.e., SML versus ULW) are presented (b, d). In panel (a), please note the different power values between SML, ULW $\left(10^{6}\right.$ cells $\left.\mathrm{mL}^{-1}\right)$ and cloud water samples $\left(10^{4}\right.$ cells $\left.\mathrm{mL}^{-1}\right)$.

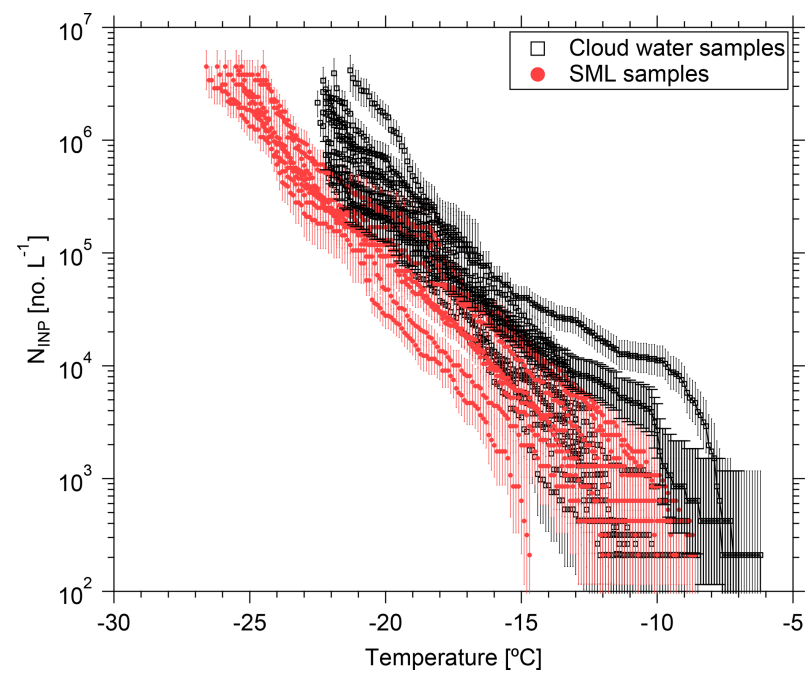

Figure 22. $N_{\text {INP }}$ of SML seawater $(n=9)$ and cloud water $(n=13)$ as a function of temperature.

rent weather forecast model of the German Weather Service. The numerical calculation of the weather forecast is achieved by using information on the underlying orography and land use, as well as boundary data for all meteorological fields. The needed boundary and initial fields will be derived from reanalysis data and/or input parameters from coarse-resolved weather model data. The first simulations show that clouds frequently occurred at heights of 700 to $800 \mathrm{~m}$ (Fig. 23), in strong agreement with the observations. This demonstrates that clouds at Mt. Verde can form solely due to the local meteorological conditions and not necessarily due to orographic effects. Accordingly, the combination of ground-based aerosol measurements and in-cloud measurements at the top of Mt. Verde will be applied to examine important chemical transformations of marine aerosol particles during horizontal and vertical transport within the MBL. From the measurements presented here, a transfer of oceanderived compounds to the cloud level is very likely. To link and understand both measurement sites in terms of important multiphase chemical pathways, more detailed modeling studies regarding the multiphase chemistry within the MBL, combined with the impact of horizontal and vertical transport on the aerosol and cloud droplet composition, will be performed by using different model approaches (more details in the Supplement). In general, both projected model studies will focus on (i) determining the oxidation pathways of key marine organics and (ii) the evolution of aerosol and cloud droplet acidity by chemical aging of the sea spray aerosol. The model results will finally be linked to the measurements and compared with the measured aerosol particle concentration and composition as well as the in-cloud measurements at the top of Mt. Verde. 


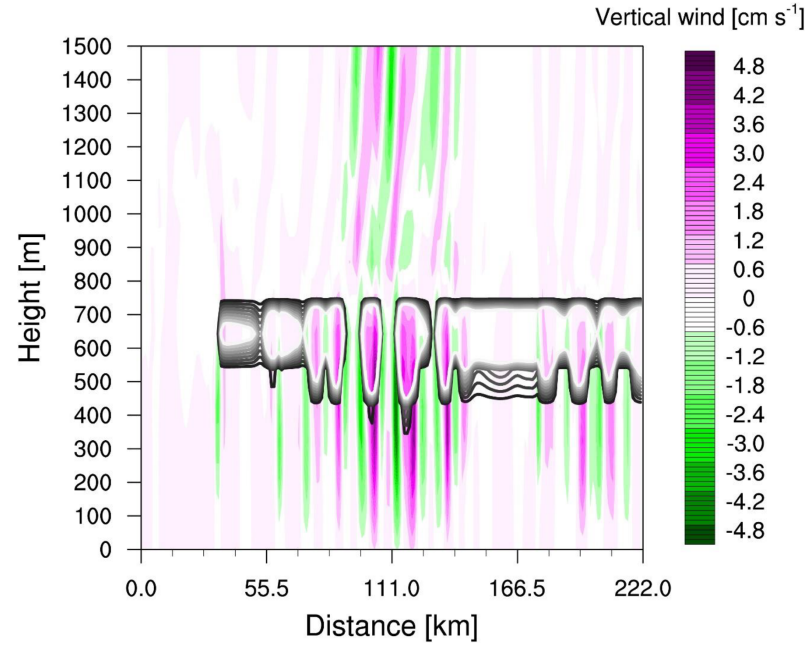

Figure 23. Modeled 2D vertical wind field on 5 October after $12 \mathrm{~h}$ of simulation time. The model domain spans $222 \mathrm{~km}$ of length and $1.5 \mathrm{~km}$ of height. The black contour lines represent the simulated cloud liquid water content (with a minimum of $0.01 \mathrm{~g} \mathrm{~m}^{-3}$ and a maximum of $0.5 \mathrm{~g} \mathrm{~m}^{-3}$ ). The more dense the lines, the higher the simulated liquid water content of the clouds.

\subsubsection{Development of a new organic matter emission source function}

The link of ocean biota to marine-derived organic aerosol particles has been recognized (e.g., O'Dowd et al., 2004). However, the usage of a single parameter like chl $a$ as an indicator for biological processes and its implementation in oceanic emission parameterizations is insufficient as it does not reflect pelagic community structure and associated ecosystem functions. It is strongly suggested to incorporate process-based models for marine biota and OM rather than relying on simple parameterizations (Burrows et al., 2014). A major challenge is the high level of complexity of the OM in marine aerosol particles as well as in the bulk water and the SML as potential sources. Within MarParCloud modeling, a new source function for the oceanic emission of $\mathrm{OM}$ will be developed as a combination of the sea spray source function of Salter et al. (2015) and a new scheme for the enrichment of OM within the emitted sea spray droplets. This new scheme will be based on the Langmuir adsorption of organic species at the bubble films. The oceanic emissions will be parameterized following Burrows et al. (2014), whereby the OM is partitioned into several classes based on its physicochemical properties. The measured concentration of the species in the ocean surface water and the SML (e.g., lipids, carbohydrates and proteins) will be included in the parameterization scheme. Finally, size-class-resolved enrichment functions of the organic species groups within the jet droplets will be included in the new scheme. The new emission scheme will be implemented to the aerosol chemical transport model MUSCAT (Multi-Scale Chemistry Aerosol Transport). MUSCAT is able to treat the atmospheric transport and chemical transformation of different traces gases as well as particle properties. In addition to advection and turbulent diffusion, sedimentation as well as dry and wet deposition through the transport processes are considered, too. MUSCAT is coupled with COSMO, which provides MUSCAT with all needed meteorological fields (Wolke et al., 2004). The multiscale model system COSMO-MUSCAT will be used further to validate the emission scheme of OM via small-scale and mesoscale simulations.

\section{Summary and conclusion}

Within MarParCloud and with substantial contributions from MARSU, an interdisciplinary campaign in the remote tropical ocean took place in autumn 2017. This paper delivers a description of the measurement objectives, including the first results, and provides an overview for upcoming detailed investigations.

Typical for the measurement site, the wind direction was almost constant from the northeasterly sector $\left(30-60^{\circ}\right)$. The analysis of the air masses and dust measurements showed that dust input was generally low; however, partly moderate dust influences were observed. Based on very similar particle number size distributions at the ground and mountain sites, it was found that the MBL was generally well mixed, with a few exceptions, and the MBL height ranged from 600 to $1100 \mathrm{~m}$. Differences in the PNSDs arose from the dust influences. The chemical composition of the aerosol particles and the cloud water indicated that the coarse-mode particles served as efficient CCN. Furthermore, lipid biomarkers were present in the aerosol particles in typical concentrations of marine background conditions and anticorrelated with dust concentrations.

From the satellite cloud observations and supporting modeling studies, it was suggested that the majority of low-level clouds observed over the islands formed over the ocean and could form solely due to the local meteorological conditions. Therefore, ocean-derived aerosol particles, e.g., sea salt and marine biogenic compounds, might be expected to have some influence on cloud formation. The presence of compounds of marine origin in cloud water samples (e.g., sodium, methanesulfonic acid, FAAs, TEPs, distinct DOM classes) at Mt. Verde supported an ocean-cloud link. The transfer of oceanderived compounds, e.g., TEPs, from the ocean to the atmosphere was confirmed in controlled tank measurements. The DOM composition of the cloud waters was consistent with the SML and bulk water composition and partly different from the aerosol particle composition. However, based on the findings that (biologically active) INPs were mainly present in supermicron aerosol particles that are not suggested to undergo strong enrichment during ocean-atmosphere transfer as well as the INP abundance in seawater and in cloud wa- 
ter, other non-marine sources most likely significantly contributed to the local INP concentration.

The bulk water and SML analysis comprised a wide spectrum of biological and chemical constituents and consistently showed enrichment in the SML. Especially for the complex OM characterization, some of the methods presented here have been used for the first time for such diverse sets of marine samples (e.g., DOM fractioning, metabolome studies with DART-HR-MS). Chl $a$ concentrations were typical for oligotrophic regions such as Cape Verde. The pigment composition indicated the presence of cyanobacteria, haptophytes and diatoms with a temporal change in dominating groups (from cyanobacteria to diatoms) suggesting the start of the diatom bloom. Possible linkages to the background dust input will be resolved. Concentrations and SML enrichment of DOC were comparable to previous campaigns at the same location. For the DOC as a sum parameter, the two applied sampling techniques (manual and catamaran glass plate) provided very similar results. However, whether this is also true for the various compound classes remains to be evaluated. Lipids established an important organic compound group in the SML, and a selective enrichment of surface-active lipid classes within the SML was found. Observed enrichments also indicated biotic and/or abiotic lipid degradation processing within the SML. The temporal variability of bacterial abundance was studied and provided the first colocated SML and cloud water measurements for this particular oceanic province. Whether the strong day-to-day variability of absolute cell numbers in the SML and bulk water was derived from changing water bodies or altered meteorological forcing needs to be further elucidated. Regarding mercury species, results indicate that the SML is the major compartment where (dissolved plus particulate) $\mathrm{Hg}$ was enriched, while $\mathrm{MeHg}$ was more likely concentrated in the bulk water, underlining the importance of the SML in $\mathrm{Hg}$ enrichment dependent on OM.

For the trace gases, a variety of conditions were observed, showing influences from the ocean and the long-range transport of pollutants. High amounts of sunlight and high humidity in this tropical region are key in ensuring that primary and secondary pollutants (e.g., ethene and ozone) are removed effectively; however, additional processes need to be regarded. Measurements within the marine boundary layer and at the ocean-atmosphere interface, such as those shown here, are essential to understand the various roles of these short-lived trace gases with respect to atmospheric variability and wider climatic changes. The Cape Verde islands are likely a source region for HONO, and the potential of the SML to form secondary particles needs to be further elucidated.
This paper shows the proof of concept of the connection between organic matter emission from the ocean to the atmosphere and up to the cloud level. We clearly see a link between the ocean and the atmosphere as (i) the particles measured at the surface are well mixed within the marine boundary layer up to cloud level, and (ii) ocean-derived compounds can be found in the (submicron) aerosol particles at mountain height and in the cloud water. The organic measurements will be implemented in a new source function for the oceanic emission of OM. From the perspective of particle number concentrations, the SSA (i.e., primary marine aerosol) contributions to both CCN and INPs are, however, rather limited. Furthermore, CCN and INP populations are much lower during clean marine periods than during dust periods. These findings underline the fact that further in-depth studies differentiating between submicron and supermicron particles as well as between aerosol number and aerosol mass are strongly required. A clear description of any potential transfer patterns and the quantification of additional important sources must await the complete analysis of all the samples collected. The main current objective is to finalize all measurements and interconnect the meteorological, physical, biological and chemical parameters also to be implemented as key variables in model runs. Finally, we aim to achieve a comprehensive picture of the seawater and atmospheric conditions for the period of the campaign to elucidate the abundance, cycling and transfer mechanisms of organic matter between the marine environmental compartments. 


\section{Appendix A: List of acronyms}

\begin{tabular}{|c|c|}
\hline APS & Aerodynamic particle sizer \\
\hline $\mathrm{CCN}$ & Cloud condensation nuclei \\
\hline $\mathrm{CCNC}$ & Cloud condensation nuclei counter \\
\hline CDOM & Chromophoric dissolved organic matter \\
\hline $\operatorname{chl} a$ & Chlorophyll $a$ \\
\hline COSMO & Consortium for Small-scale Modelling-Multiscale Chemistry Aerosol Transport Model \\
\hline CTD & Conductivity-temperature-depth sensor \\
\hline CVAO & Cape Verde atmospheric observatory \\
\hline CVFZ & Cape Verde frontal zone \\
\hline CVOO & Cape Verde ocean observatory \\
\hline DART-QTOF-MS & Direct analysis in real-time quadrupole time-of-flight mass spectrometry \\
\hline DegLip & Lipid degradation products \\
\hline DL & Dissolved lipids \\
\hline DMS & Dimethyl sulfide \\
\hline DOC & Dissolved organic carbon \\
\hline DOM & Dissolved organic matter \\
\hline ECWMF & European Centre for Medium-Range Weather Forecasts \\
\hline EBUS & Eastern boundary upwelling system \\
\hline $\mathrm{EF}$ & Enrichment factor (analyte concentration in the SML with respect to the analyte concentration in the bulk water) \\
\hline ETNA & Eastern tropical North Atlantic \\
\hline FAAs & Free amino acids \\
\hline Go : PAM & Gothenburg potential aerosol mass reactor \\
\hline HONO & Nitrous acid \\
\hline HYSPLIT & Hybrid single-particle lagrangian integrated trajectory \\
\hline $\mathrm{INP}(\mathrm{s})$ & Ice-nucleating particle(s) \\
\hline LOPAP & Long-path absorption photometer \\
\hline LMWAs & Low-molecular-weight acids \\
\hline LMWNs & Low-molecular-weight neutrals \\
\hline MarParCat & Catamaran with glass plates for SML sampling \\
\hline MarParCloud & Marine biological production, organic aerosol Particles and marine Clouds: a process chain \\
\hline MARSU & MARine atmospheric Science Unravelled \\
\hline MBL & Marine boundary layer \\
\hline $\mathrm{MeHg}$ & Methylmercury (MeHg) \\
\hline Mt. Verde & Highest point of São Vicente island (744 m) \\
\hline MUSCAT & Multi-Scale Chemistry Aerosol Transport \\
\hline NACW & North Atlantic Central Water masses \\
\hline$N_{\mathrm{CCN}}$ & Cloud condensation nuclei number concentration \\
\hline$N_{\text {INP }}$ & Numbers of INPs \\
\hline $\mathrm{OH}$ & Hydroxyl radical \\
\hline OFR & Oxidation flow reactor \\
\hline $\mathrm{OM}$ & Organic matter \\
\hline $\mathrm{OMZ}$ & Oxygen minimum zone \\
\hline (O) VOCs & (Oxygenated) volatile organic compounds \\
\hline $\mathrm{PM}_{1}$ & Particulate matter (aerosol particles) smaller than $1 \mu \mathrm{m}$ \\
\hline $\mathrm{PM}_{10}$ & Particulate matter (aerosol particles) smaller than $10 \mu \mathrm{m}$ \\
\hline PNSDs & Particle number size distributions \\
\hline POM & Particulate organic matter \\
\hline PVM & Particle volume monitor \\
\hline SACW & South Atlantic Central Water mass \\
\hline SAL & Saharan air layer \\
\hline SASs & Surface-active substances and/or surfactants \\
\hline SML & Sea surface microlayer \\
\hline SOA & Secondary organic aerosol \\
\hline SSA & Sea spray aerosol \\
\hline SMPS & Scanning mobility particle sizer \\
\hline TEPs & Transparent exopolymer particles \\
\hline TSP & Total suspended particulate \\
\hline $\mathrm{TM}$ & Transmission mode \\
\hline WSOM & Water-soluble organic matter \\
\hline
\end{tabular}


Data availability. The data are available through the World Data Centre PANGAEA under the following links: https://doi.pangaea. de/10.1594/PANGAEA.910693 (van Pinxteren, 2020a; Table 2) and https://doi.pangaea.de/10.1594/PANGAEA.910692 (van Pinxteren, 2020b; Table 1).

Supplement. The supplement related to this article is available online at: https://doi.org/10.5194/acp-20-6921-2020-supplement.

Author contributions. MvP, KWF, NT and HH organized and coordinated the MarParCloud campaign. MvP, KWF, NT, CS, EB, XG, JV, HW, TBR, MR, CL, BG, TL, LW, JL and HC participated in the campaign. All authors were involved in the analysis, data evaluation and discussion of the results. $\mathrm{MvP}$ and $\mathrm{HH}$ wrote the paper with contributions from all coauthors. All coauthors proofread and commented on the paper.

Competing interests. The authors declare that they have no conflict of interest.

Special issue statement. This article is part of the special issue "Marine organic matter: from biological production in the ocean to organic aerosol particles and marine clouds (ACP/OS inter-journal SI)". It is not associated with a conference.

Acknowledgements. We acknowledge the CVAO site manager, Luis Neves, and the Atmospheric Measurement Facility at the National Centre for Atmospheric Science (AMF, NCAS). The authors acknowledge Thomas Conrath, Tobias Spranger and Pit Strehl for their support during fieldwork. Kerstin Lerche from the HelmholtzZentrum für Umweltforschung GmbH - UFZ (Magdeburg) is acknowledged for the pigment measurements. The authors thank Susanne Fuchs, Anett Dietze, Sontje Krupka, René Rabe and Anke Rödger for providing additional data and filter samples, as well as Elisa Berdalet for the discussion about the pigment concentrations. Kay Weinhold, Thomas Müller and Alfred Wiedensohler are acknowledged for their data support. We thank Johannes Lampel for providing the photograph in Fig. 1. In addition, the use of SEVIRI data and NWCSAF processing software, distributed by EUMETSAT and obtained from the TROPOS satellite archive, is acknowledged. María Eugenia Monge is a research staff member from CONICET (Consejo Nacional de Investigaciones Científicas y Técnicas, Argentina). Ryan Pereira thanks Juliane Bischoff and Sara Trojahn for technical support. We also thank the Monaco Explorations program as well as captain and crew of MV YERSIN for supporting the wave glider deployment. Finally, the authors thank the anonymous reviewers for their valuable comments and suggestions.

Financial support. This work was funded by the Leibniz Association SAW under the project "Marine biological production, organic aerosol particles and marine clouds: a Process Chain (MarPar-
Cloud)" (SAW-2016-TROPOS-2) and within the Research and Innovation Staff Exchange EU project MARSU (grant no. 69089). We received support from the European Regional Development fund by the European Union under contract no. 100188826. Jianmin Chen received funding from the Ministry of Science and Technology of China (grant no. 2016YFC0202700) and the National Natural Science Foundation of China (grant nos. 91843301, 91743202, 21527814). Sanja Frka and Blaženka Gašparović received full support from the Croatian Science Foundation under the Croatian Science Foundation project IP-2018-01-3105. Erik H. Hoffmann received financial support from the $\mathrm{PhD}$ scholarship program of the German Federal Environmental Foundation (Deutsche Bundesstiftung Umwelt, DBU, AZ: 2016/424). Sebastian Zeppenfeld received funding from the Deutsche Forschungsgemeinschaft (DFG, German Research Foundation, project 268020496-TRR 172) within the Transregional Collaborative Research Center "ArctiC Amplification: Climate Relevant Atmospheric and SurfaCe Processes, and Feedback Mechanisms (AC)3".

Review statement. This paper was edited by Paul Zieger and reviewed by two anonymous referees.

\section{References}

Abbatt, J. P. D., Leaitch, W. R., Aliabadi, A. A., Bertram, A. K., Blanchet, J. P., Boivin-Rioux, A., Bozem, H., Burkart, J., Chang, R. Y. W., Charette, J., Chaubey, J. P., Christensen, R. J., Cirisan, A., Collins, D. B., Croft, B., Dionne, J., Evans, G. J., Fletcher, C. G., Gali, M., Ghahremaninezhad, R., Girard, E., Gong, W. M., Gosselin, M., Gourdal, M., Hanna, S. J., Hayashida, H., Herber, A. B., Hesaraki, S., Hoor, P., Huang, L., Hussherr, R., Irish, V. E., Keita, S. A., Kodros, J. K., Kollner, F., Kolonjari, F., Kunkel, D., Ladino, L. A., Law, K., Levasseur, M., Libois, Q., Liggio, J., Lizotte, M., Macdonald, K. M., Mahmood, R., Martin, R. V., Mason, R. H., Miller, L. A., Moravek, A., Mortenson, E., Mungall, E. L., Murphy, J. G., Namazi, M., Norman, A. L., O’Neill, N. T., Pierce, J. R., Russell, L. M., Schneider, J., Schulz, H., Sharma, S., Si, M., Staebler, R. M., Steiner, N. S., Thomas, J. L., von Salzen, K., Wentzell, J. J. B., Willis, M. D., Wentworth, G. R., Xu, J. W., and Yakobi-Hancock, J. D.: Overview paper: New insights into aerosol and climate in the Arctic, Atmos. Chem. Phys., 19, 2527-2560, https://doi.org/10.5194/acp-19-2527-2019, 2019.

Baldauf, M., Seifert, A., Forstner, J., Majewski, D., Raschendorfer, M., and Reinhardt, T.: Operational Convective-Scale Numerical Weather Prediction with the COSMO Model: Description and Sensitivities, Mon. Weather Rev., 139, 3887-3905, https://doi.org/10.1175/mwr-d-10-05013.1, 2011.

Batrakova, N., Travnikov, O., and Rozovskaya, O.: Chemical and physical transformations of mercury in the ocean: a review, Ocean Sci., 10, 1047-1063, https://doi.org/10.5194/os-10-10472014, 2014.

Bertram, T. H., Cochran, R. E., Grassian, V. H., and Stone, E. A.: Sea spray aerosol chemical composition: elemental and molecular mimics for laboratory studies of heterogeneous and multiphase reactions, Chem. Soc. Rev., 47, 2374-2400, https://doi.org/10.1039/c7cs00008a, 2018. 
Bigg, E. K. and Leck, C.: The composition of fragments of bubbles bursting at the ocean surface, J. Geophys. Res.-Atmos., 113, D11209, https://doi.org/10.1029/2007jd009078, 2008.

Blum, J. D., Popp, B. N., Drazen, J. C., Anela Choy, C., and Johnson, M. W.: Methylmercury production below the mixed layer in the North Pacific Ocean, Nat. Geosci., 6, 879-884, https://doi.org/10.1038/ngeo1918, 2013.

Bonsang, B., Gros, V., Peeken, I., Yassaa, N., Bluhm, K., Zoellner, E., Sarda-Esteve, R., and Williams, J.: Isoprene emission from phytoplankton monocultures, relationship with chlorophyll, cell volume, and carbon content, Environ. Chem., 7, 554-563, https://doi.org/10.1071/EN091562010.

Bowman, K. L., Hammerschmidt, C. R., Lamborg, C. H., and Swarr, G.: Mercury in the North Atlantic Ocean: The U.S. GEOTRACES zonal and meridional sections, Deep-Sea Res. Pt. II, 116, 251-261, https://doi.org/10.1016/j.dsr2.2014.07.004, 2015.

Brandt, P., Bange, H. W., Banyte, D., Dengler, M., Didwischus, S. H., Fischer, T., Greatbatch, R. J., Hahn, J., Kanzow, T., Karstensen, J., Krortzinger, A., Krahmann, G., Schmidtko, S., Stramma, L., Tanhua, T., and Visbeck, M.: On the role of circulation and mixing in the ventilation of oxygen minimum zones with a focus on the eastern tropical North Atlantic, Biogeosciences, 12, 489-512, https://doi.org/10.5194/bg-12-489-2015, 2015.

Brooks, S. D. and Thornton, D. C. O.: Marine Aerosols and Clouds, in: Annual Review of Marine Science, Vol 10, edited by: Carlson, C. A. and Giovannoni, S. J., Annual Review of Marine Science, Annual Reviews, Palo Alto, 289-313, 2018.

Brueggemann, M., Hayeck, N., and George, C.: Interfacial photochemistry at the ocean surface is a global source of organic vapors and aerosols, Nat. Commun., 9, 2101, https://doi.org/10.1038/s41467-018-04528-7, 2018.

Burrows, S. M., Hoose, C., Poschl, U., and Lawrence, M. G.: Ice nuclei in marine air: biogenic particles or dust?, Atmos. Chem. Phys., 13, 245-267, https://doi.org/10.5194/acp-13-2452013, 2013.

Burrows, S. M., Ogunro, O., Frossard, A. A., Russell, L. M., Rasch, P. J., and Elliott, S. M.: A physically based framework for modeling the organic fractionation of sea spray aerosol from bubble film Langmuir equilibria, Atmos. Chem. Phys., 14, 1360113629, https://doi.org/10.5194/acp-14-13601-2014, 2014.

Carpenter, L. J., Fleming, Z. L., Read, K. A., Lee, J. D., Moller, S. J., Hopkins, J. R., Purvis, R. M., Lewis, A. C., Müller, K., Heinold, B., Herrmann, H., Fomba, K. W., van Pinxteren, D., Müller, C., Tegen, I., Wiedensohler, A., Müller, T., Niedermeier, N., Achterberg, E. P., Patey, M. D., Kozlova, E. A., Heimann, M., Heard, D. E., Plane, J. M. C., Mahajan, A., Oetjen, H., Ingham, T., Stone, D., Whalley, L. K., Evans, M. J., Pilling, M. J., Leigh, R. J., Monks, P. S., Karunaharan, A., Vaughan, S., Arnold, S. R., Tschritter, J., Pohler, D., Friess, U., Holla, R., Mendes, L. M., Lopez, H., Faria, B., Manning, A. J., and Wallace, D. W. R.: Seasonal characteristics of tropical marine boundary layer air measured at the Cape Verde Atmospheric Observatory, J. Atmos. Chem., 67, 87-140, https://doi.org/10.1007/s10874-011-9206-1, 2010.

Chen, Q., Sherwen, T., Evans, M., and Alexander, B.: DMS oxidation and sulfur aerosol formation in the marine troposphere: a focus on reactive halogen and multiphase chemistry, Atmos. Chem. Phys., 18, 13617-13637, https://doi.org/10.5194/acp-1813617-2018, 2018.
Ciuraru, R., Fine, L., van Pinxteren, M., D'Anna, B., Herrmann, H., and George, C.: Unravelling New Processes at Interfaces: Photochemical Isoprene Production at the Sea Surface, Environ. Sci. Technol., 49, 13199-13205, https://doi.org/10.1021/acs.est.5b02388, 2015.

Cochran, R. E., Jayarathne, T., Stone, E. A., and Grassian, V. H.: Selectivity Across the Interface: A Test of Surface Activity in the Composition of Organic-Enriched Aerosols from Bubble Bursting, J. Phys. Chem. Lett., 7, 1692-1696, https://doi.org/10.1021/acs.jpclett.6b00489, 2016.

Cochran, R. E., Ryder, O. S., Grassian, V. H., and Prather, K. A.: Sea Spray Aerosol: The Chemical Link between the Oceans, Atmosphere, and Climate, Accounts Chem. Res., 50, 599-604, https://doi.org/10.1021/acs.accounts.6b00603, 2017.

Ćosović, B. and Vojvodić, V.: Voltammetric analysis of surface active substances in natural seawater, Electroanalysis, 10, 429-434, https://doi.org/10.1002/(sici)1521-4109(199805)10:6<429::Aidelan429>3.3.Co;2-z, 1998.

Cunliffe, M. and Wurl, O.: Guide to best practices to study the ocean's surface, Occasional Publications of the Marine Biological Association of the United Kingdom, Plymouth, UK, 118 pp., 2014.

Cunliffe, M., Engel, A., Frka, S., Gašparović, B., Guitart, C., Murrell, J. C., Salter, M., Stolle, C., Upstill-Goddard, R., and Wurl, O.: Sea surface microlayers: A unified physicochemical and biological perspective of the air-ocean interface, Prog. Oceanogr., 109, 104-116, https://doi.org/10.1016/j.pocean.2012.08.004, 2013.

de Leeuw, G., Andreas, E. L., Anguelova, M. D., Fairall, C. W., Lewis, E. R., O'Dowd, C., Schulz, M., and Schwartz, S. E.: Production Flux of Sea Spray Aerosol, Rev. Geophys., 49, RG2001, https://doi.org/10.1029/2010rg000349, 2011.

Demoz, B. B., Collett, J. L., and Daube, B. C.: On the Caltech Active Strand Cloudwater Collectors, Atmos. Res., 41, 47-62, https://doi.org/10.1016/0169-8095(95)00044-5, 1996.

Derrien, M. and Le Gleau, H.: MSG/SEVIRI cloud mask and type from SAFNWC, Int. J. Remote Sens., 26, 4707-4732, https://doi.org/10.1080/01431160500166128, 2005.

Engel, A., Bange, H., Cunliffe, M., Burrows, S., Friedrichs, G., Galgani, L., Herrmann, H., Hertkorn, N., Johnson, M., Liss, P., Quinn, P., Schartau, M., Soloviev, A., Stolle, C., Upstill-Goddard, R., van Pinxteren, M., and Zäncker, B.: The Ocean's Vital Skin: Toward an Integrated Understanding of the Sea Surface Microlayer, Front. Mar. Sci., 4, 165, https://doi.org/10.3389/fmars.2017.00165, 2017.

Facchini, M. C., Rinaldi, M., Decesari, S., Carbone, C., Finessi, E., Mircea, M., Fuzzi, S., Ceburnis, D., Flanagan, R., Nilsson, E. D., de Leeuw, G., Martino, M., Woeltjen, J., and O’Dowd, C. D.: Primary submicron marine aerosol dominated by insoluble organic colloids and aggregates, Geophys. Res. Lett., 35, L17814, https://doi.org/10.1029/2008g1034210, 2008.

Fiedler, B., Grundle, D. S., Schutte, F., Karstensen, J., Loscher, C. R., Hauss, H., Wagner, H., Loginova, A., Kiko, R., Silva, P., Tanhua, T., and Kortzinger, A.: Oxygen utilization and downward carbon flux in an oxygen-depleted eddy in the eastern tropical North Atlantic, Biogeosciences, 13, 5633-5647, https://doi.org/10.5194/bg-13-5633-2016, 2016.

Fomba, K. W., Müller, K., van Pinxteren, D., and Herrmann, H.: Aerosol size-resolved trace metal composition in remote 
northern tropical Atlantic marine environment: case study Cape Verde islands, Atmos. Chem. Phys., 13, 4801-4814, https://doi.org/10.5194/acp-13-4801-2013, 2013.

Fomba, K. W., Mueller, K., van Pinxteren, D., Poulain, L., van Pinxteren, M., and Herrmann, H.: Long-term chemical characterization of tropical and marine aerosols at the Cape Verde Atmospheric Observatory (CVAO) from 2007 to 2011, Atmos. Chem. Phys., 14, 8883-8904, https://doi.org/10.5194/acp-148883-2014, 2014.

Franklin, D., Poulton, J. A., Steinke, M., Young, J., Peeken, I., and Malin, G.: Dimethylsulphide, DMSP-lyase activity and microplankton community structure inside and outside of the Mauritanian upwelling, Prog. Oceanogr., 83, 134-142, 2009.

Frka, S., Kozarac, Z., and Ćosović, B.: Characterization and seasonal variations of surface active substances in the natural sea surface micro-layers of the coastal Middle Adriatic stations, Estuar. Coast. Shelf Sci., 85, 555-564, https://doi.org/10.1016/j.ecss.2009.09.023, 2009.

Frka, S., Pogorzelski, S., Kozarac, Z., and Ćosović, B.: Physicochemical Signatures of Natural Sea Films from Middle Adriatic Stations, J. Phys. Chem. A, 116, 6552-6559, https://doi.org/10.1021/jp212430a, 2012.

Gantt, B. and Meskhidze, N.: The physical and chemical characteristics of marine primary organic aerosol: a review, Atmos. Chem. Phys., 13, 3979-3996, https://doi.org/10.5194/acp13-3979-2013, 2013.

Garrett, W. D.: Collection of slick-forming materials from the sea surface, Limnol. Oceanogr., 10, 602-605, 1965.

Gašparović, B., Kozarac, Z., Saliot, A., Ćosović, B., and Möbius, D.: Physicochemical characterization of natural and ex-situ reconstructed sea-surface microlayers, J. Colloid and Interf. Sci., 208, 191-202, https://doi.org/10.1006/jcis.1998.5792, 1998a.

Gašparović, B., Vojvodić, V., and Ćosović, B.: Excretion of organic matter during an experimental phytoplankton bloom followed using o-nitrophenol as an electrochemical probe, Croat. Chem. Acta, 71, 271-284, 1998b.

Gašparović, B., Plavšić, M., Ćosović, B., and Saliot, A.: Organic matter characterization in the sea surface microlayers in the subarctic Norwegian fjords region, Mar. Chem., 105, 1-14, https://doi.org/10.1016/j.marchem.2006.12.010, 2007.

Gong, X., Wex, H., Voigtländer, J., Fomba, K. W., Weinhold, K., van Pinxteren, M., Henning, S., Müller, T., Herrmann, H., and Stratmann, F.: Characterization of aerosol particles at Cabo Verde close to sea level and at the cloud level - Part 1: Particle number size distribution, cloud condensation nuclei and their origins, Atmos. Chem. Phys., 20, 1431-1449, https://doi.org/10.5194/acp-20-1431-2020, 2020a.

Gong, X., Wex, H., van Pinxteren, M., Triesch, N., Fomba, K. W., Lubitz, J., Stolle, C., Robinson, T.-B., Müller, T., Herrmann, H., and Stratmann, F.: Characterization of aerosol particles at Cabo Verde close to sea level and at the cloud level Part 2: Ice-nucleating particles in air, cloud and seawater, Atmos. Chem. Phys., 20, 1451-1468, https://doi.org/10.5194/acp20-1451-2020, 2020b.

Hepach, H., Quack, B., Ziska, F., Fuhlbrügge, S., Atlas, E., Peeken, I., Krüger, K., and Wallace, D. W. R.: Drivers of diel and regional variations of halocarbon emissions from the tropical North East Atlantic, Atmos. Chem. Phys., 14, 1255-1275, 10.5194/acp-141255-2014, 2014.
Herrmann, H., Schaefer, T., Tilgner, A., Styler, S. A., Weller, C., Teich, M., and Otto, T.: Tropospheric Aqueous-Phase Chemistry: Kinetics, Mechanisms, and Its Coupling to a Changing Gas Phase, Chem. Rev., 115, 4259-4334, https://doi.org/10.1021/cr500447k, 2015.

Hoffmann, E. H., Tilgner, A., Schrödner, R., Bräuer, P., Wolke, R., Herrmann, H.: An advanced modeling study on the impacts and atmospheric implications of multiphase dimethyl sulfide chemistry, P. Natl. Acad. Sci. USA, 113, 11776-11781, 2016.

Hoppel, W. A., Frick, G. M., and Larson, R. E.: Effect of nonprecipitating clouds on the aerosol size distribution in the marine boundary-layer, Geophys. Res. Lett., 13, 125-128, https://doi.org/10.1029/GL013i002p00125, 1986.

Horowitz, L. W., Walters, S., Mauzerall, D. L., Emmons, L. K., Rasch, P. J., Granier, C., Tie, X. X., Lamarque, J. F., Schultz, M. G., Tyndall, G. S., Orlando, J. J., and Brasseur, G. P.: A global simulation of tropospheric ozone and related tracers: Description and evaluation of MOZART, version 2, J. Geophys. Res.-Atmos., 108, ACH 16-1-ACH 16-18, https://doi.org/10.1029/2002jd002853, 2003.

Hu, W., Niu, H. Y., Murata, K., Wu, Z. J., Hu, M., Kojima, T., and Zhang, D. Z.: Bacteria in atmospheric waters: Detection, characteristics and implications, Atmos. Environ., 179, 201-221, https://doi.org/10.1016/j.atmosenv.2018.02.026, 2018.

Huber, S. A., Balz, A., Abert, M., and Pronk, W.: Characterisation of aquatic humic and non-humic matter with size-exclusion chromatography-organic carbon detection-organic nitrogen detection (LC-OCD-OND), Water Res., 45, 879-885, 2011.

Karstensen, J., Fiedler, B., Schutte, F., Brandt, P., Kortzinger, A., Fischer, G., Zantopp, R., Hahn, J., Visbeck, M., and Wallace, D.: Open ocean dead zones in the tropical North Atlantic Ocean, Biogeosciences, 12, 2597-2605, https://doi.org/10.5194/bg-122597-2015, 2015.

Kawamura, K., Ishimura, Y., and Yamazaki, K.: Four years' observations of terrestrial lipid class compounds in marine aerosols from the western North Pacific, Global Biogeochem. Cy., 17, 1003, https://doi.org/10.1029/2001GB001810, 2003.

Kaylor, A., Dwivedi, P., Pittman, J. J., Monge, M. E., Cheng, G., Li, S., and Fernandez, F. M.: Plasma-spray ionization (PLASI): a multimodal atmospheric pressure ion source for liquid stream analysis, J. Am. Soc. Mass Spectr., 25, 1788-1793, https://doi.org/10.1007/s13361-014-0948-2, 2014.

Kroflič, A., Frka, S., Simmel, M., Wex, H., and Grgić, I.: Size-Resolved Surface-Active Substances of Atmospheric Aerosol: Reconsideration of the Impact on Cloud Droplet Formation, Environ. Sci. Technol., 52, 9179-9187, https://doi.org/10.1021/acs.est.8b02381, 2018.

Law, C. S., Breviere, E., de Leeuw, G., Garcon, V., Guieu, C., Kieber, D. J., Kontradowitz, S., Paulmier, A., Quinn, P. K., Saltzman, E. S., Stefels, J., and von Glasow, R.: Evolving research directions in Surface Ocean-Lower Atmosphere (SOLAS) science, Environ. Chem., 10, 1-16, https://doi.org/10.1071/en12159, 2013.

Lelieveld, J. and Crutzen, P. J.: The role of clouds in tropospheric photochemistry, J. Atmos. Chem., 12, 229-267, https://doi.org/10.1007/BF00048075, 1991.

Lewis, A. C., Hopkins, J. R., Carpenter, L. J., Stanton, J., Read, K. A., and Pilling, M. J.: Sources and sinks of acetone, methanol, and acetaldehyde in North Atlantic marine air, Atmos. Chem. 
Phys., 5, 1963-1974, https://doi.org/10.5194/acp-5-1963-2005, 2005.

Li, T., Wang, Y., Mao, H., Wang, S., Talbot, R. W., Zhou, Y., Wang, Z., Nie, X., and Qie, G.: Insights on Chemistry of Mercury Species in Clouds over Northern China: Complexation and Adsorption, Environ. Sci. Technol., 52, 5125-5134, https://doi.org/10.1021/acs.est.7b06669, 2018.

Marandino, C. A., De Bruyn, W. J., Miller, S. D., and Saltzman, E. S.: DMS air/sea flux and gas transfer coefficients from the North Atlantic summertime coccolithophore bloom, Geophys. Res. Lett., 35, L23812, https://doi.org/10.1029/2008g1036370, 2008.

Marty, J. C., Saliot, A., Buat-Ménard, P., Chesselet, R., and Hunter, K. A.: Relationship between the lipid compositions of marine aerosols, the sea surface microlayer, and subsurface water, J. Geophys. Res.-Oceans, 84, 5707-5716, https://doi.org/10.1029/JC084iC09p05707, 1979.

McCluskey, C. S., Hill, T. C. J., Humphries, R. S., Rauker, A. M., Moreau, S., Strutton, P. G., Chambers, S. D., Williams, A. G., McRobert, I., Ward, J., Keywood, M. D., Harnwell, J., Ponsonby, W., Loh, Z. M., Krummel, P. B., Protat, A., Kreidenweis, S. M., and DeMott, P. J.: Observations of Ice Nucleating Particles Over Southern Ocean Waters, Geophys. Res. Lett., 45, 11989-11997, 2018a.

McCluskey, C. S., Ovadnevaite, J., Rinaldi, M., Atkinson, J., Belosi, F., Ceburnis, D., Marullo, S., Hill, T. C. J., Lohmann, U., Kanji, Z. A., O'Dowd, C., Kreidenweis, S. M., and DeMott., P. J.: Marine and Terrestrial Organic Ice-Nucleating Particles in Pristine Marine to Continentally Influenced Northeast Atlantic Air Masses, J. Geophys. Res.-Atmos., 123, 6196-6212, 2018 b.

McKay, W. A., Turner, M. F., Jones, B. M. R., and Halliwell, C. M.: Emissions of hydrocarbons from marine phytoplankton - Some results from controlled laboratory experiments, Atmos. Environ., 30, 2583-2593, https://doi.org/10.1016/1352-2310(95)00433-5, 1996.

Middlebrook, A. M., Murphy, D. M., and Thomson, D. S.: Observations of organic material in individual marine particles at Cape Grim during the First Aerosol Characterization Experiment (ACE 1), J. Geophys. Res.-Atmos., 103, 16475-16483, https://doi.org/10.1029/97JD03719, 1998.

Mochida, M., Kitamori, Y., Kawamura, K., Nojiri, Y., and Suzuki, K.: Fatty acids in the marine atmosphere: Factors governing their concentrations and evaluation of organic films on sea-salt particles, J. Geophys. Res.-Atmos., 107, 4325, https://doi.org/10.1029/2001JD001278, 2001.

Modini, R. L., Frossard, A. A., Ahlm, L., Russell, L. M., Corrigan, C. E., Roberts, G. C., Hawkins, L. N., Schroder, J. C., Bertram, A. K., Zhao, R., Lee, A. K. Y., Abbatt, J. P. D., Lin, J., Nenes, A., Wang, Z., Wonaschutz, A., Sorooshian,A., Noone, K. J., Jonsson, H., Seinfeld, J. H., Toom-Sauntry, D., Macdonald, A. M., and Leaitch, W. R.: Primary marine aerosol-cloud interactions off the coast of California, J. Geophys. Res.-Atmos., 120, 4282-4303, https://doi.org/10.1002/2014jd022963, 2015.

Müller, C., Iinuma, Y., Karstensen, J., van Pinxteren, D., Lehmann, S., Gnauk, T., and Herrmann, H.: Seasonal variation of aliphatic amines in marine sub-micrometer particles at the Cape Verde islands, Atmos. Chem. Phys., 9, 9587-9597, https://doi.org/10.5194/acp-9-9587-2009, 2009.
Müller, K., Lehmann, S., van Pinxteren, D., Gnauk, T., Niedermeier, N., Wiedensohler, A., and Herrmann, H.: Particle characterization at the Cape Verde atmospheric observatory during the 2007 RHaMBLe intensive, Atmos. Chem. Phys., 10, 2709-2721, https://doi.org/10.5194/acp-10-2709-2010, 2010.

Mustaffa, N. I. H., Ribas-Ribas, M., and Wurl, O.: Highresolution variability of the enrichment of fluorescence dissolved organic matter in the sea surface microlayer of an upwelling region, Elementa-Science of the Anthropocene, 5, 52, https://doi.org/10.1525/elementa.242, 2017.

Mustaffa, N. I. H., Badewien, T. H., Ribas-Ribas, M., and Wurl, O.: High-resolution observations on enrichment processes in the sea-surface microlayer, Sci. Rep., 8, 13122, https://doi.org/10.1038/s41598-018-31465-8, 2018.

O’Dowd, C. D., Facchini, M. C., Cavalli, F., Ceburnis, D., Mircea, M., Decesari, S., Fuzzi, S., Yoon, Y. J., and Putaud, J. P.: Biogenically driven organic contribution to marine aerosol, Nature, 431, 676-680, https://doi.org/10.1038/Nature02959, 2004.

Ovadnevaite, J., O'Dowd, C., Dall'Osto, M., Ceburnis, D., Worsnop, D. R., and Berresheim, H.: Detecting high contributions of primary organic matter to marine aerosol: A case study, Geophys. Res. Lett., 38, L02807, https://doi.org/10.1029/2010gl046083, 2011.

Pagnone, A., Volker, C., and Ye, Y.: Processes affecting dissolved iron across the Subtropical North Atlantic: a model study, Ocean Dynam., 69, 989-1007, https://doi.org/10.1007/s10236019-01288-w, 2019.

Pastor, M. V., Pelegri, J. L., Hernandez-Guerra, A., Font, J., Salat, J., and Emellanov, M.: Water and nutrient fluxes off Northwest Africa, Cont. Shelf Res., 28, 915-936, https://doi.org/10.1016/j.csr.2008.01.011, 2008.

Patel, A. and Rastogi, N.: Chemical Composition and Oxidative Potential of Atmospheric PM10 over the Arabian Sea, ACS Earth Space Chem., 4, 112-121, https://doi.org/10.1021/acsearthspacechem.9b00285, 2020.

Patey, M. D., Achterberg, E. P., Rijkenberg, M. J., and Pearce, R.: Aerosol time-series measurements over the tropical Northeast Atlantic Ocean: Dust sources, elemental composition and mineralogy, Mar. Chem., 174, 103-119, https://doi.org/10.1016/j.marchem.2015.06.004, 2015.

Pereira, R., Ashton, I., Sabbaghzadeh, B., Shutler, J. D., and UpstillGoddard, R. C.: Reduced air-sea $\mathrm{CO}_{2}$ exchange in the Atlantic Ocean due to biological surfactants, Nat. Geosci., 11, 492-496, https://doi.org/10.1038/s41561-018-0136-2, 2018.

Petters, M. D. and Kreidenweis, S. M.: A single parameter representation of hygroscopic growth and cloud condensation nucleus activity, Atmos. Chem. Phys., 7, 1961-1971, https://doi.org/10.5194/acp-7-1961-2007, 2007.

Prather, K. A., Bertram, T. H., Grassian, V. H., Deane, G. B., Stokes, M. D., DeMott, P. J., Aluwihare, L. I., Palenik, B. P., Azam, F., Seinfeld, J. H., Moffet, R. C., Molina, M. J., Cappa, C. D., Geiger, F. M., Roberts, G. C., Russell, L. M., Ault, A. P., Baltrusaitis, J., Collins, D. B., Corrigan, C. E., Cuadra-Rodriguez, L. A., Ebben, C. J., Forestieri, S. D., Guasco, T. L., Hersey, S. P., Kim, M. J., Lambert, W. F., Modini, R. L., Mui, W., Pedler, B. E., Ruppel, M. J., Ryder, O. S., Schoepp, N. G., Sullivan, R. C., and Zhao, D.: Bringing the ocean into the laboratory to probe the chemical complexity of 
sea spray aerosol, P. Natl. Acad. Sci. USA, 110, 7550-7555, https://doi.org/10.1073/pnas.1300262110, 2013.

Putaud, J. P., Van Dingenen, R., Mangoni, M., Virkkula, A., Raes, F., Maring, H., Prospero, J. M., Swietlicki, E., Berg, O. H., Hillamo, R., and Mäkelä, T.: Chemical mass closure and assessment of the origin of the submicron aerosol in the marine boundary layer and the free troposphere at Tenerife during ACE-2, Tellus B, 52, 141-168, https://doi.org/10.1034/j.16000889.2000.00056.x, 2000.

Quinn, P. K., Collins, D. B., Grassian, V. H., Prather, K. A., and Bates, T. S.: Chemistry and Related Properties of Freshly Emitted Sea Spray Aerosol, Chem. Rev., 115, 4383-4399, https://doi.org/10.1021/cr500713g, 2015.

Quinn, P. K., Coffman, D. J., Johnson, J. E., Upchurch, L. M., and Bates, T. S.: Small fraction of marine cloud condensation nuclei made up of sea spray aerosol, Nat. Geosci., 10, 674-679, https://doi.org/10.1038/ngeo3003, 2017.

Rahlff, J., Stolle, C., Giebel, H. A., Brinkhoff, T., RibasRibas, M., Hodapp, D., and Wurl, O.: High wind speeds prevent formation of a distinct bacterioneuston community in the sea-surface microlayer, Fems Microbiol. Ecol., 93, https://doi.org/10.1093/femsec/fix041, 2017.

Rastelli, E., Corinaldesi, C., Dell'Anno, A., Lo Martire, M., Greco, S., Facchini, M. C., Rinaldi, M., O'Dowd, C., Ceburnis, D., and Danovaro, R.: Transfer of labile organic matter and microbes from the ocean surface to the marine aerosol: an experimental approach, Sci. Rep., 7, 11475, https://doi.org/10.1038/s41598-01710563-z, 2017.

Read, K. A., Mahajan, A. S., Carpenter, L. J., Evans, M. J., Faria, B. V. E., Heard, D. E., Hopkins, J. R., Lee, J. D., Moller, S. J., Lewis, A. C., Mendes, L., McQuaid, J. B., Oetjen, H., Saiz-Lopez, A., Pilling, M. J., and Plane, J. M. C.: Extensive halogen-mediated ozone destruction over the tropical Atlantic Ocean, Nature, 453, 1232-1235, https://doi.org/10.1038/nature07035, 2008.

Read, K. A., Carpenter, L. J., Arnold, S. R., Beale, R., Nightingale, P. D., Hopkins, J. R., Lewis, A. C., Lee, J. D., Mendes, L., and Pickering, S. J.: Multiannual Observations of Acetone, Methanol, and Acetaldehyde in Remote Tropical Atlantic Air: Implications for Atmospheric OVOC Budgets and Oxidative Capacity, Environ. Sci. Technol., 46, 11028-11039, https://doi.org/10.1021/es302082p, 2012.

Roberts, G. C. and Nenes, A.: A continuous-flow streamwise thermal-gradient $\mathrm{CCN}$ chamber for atmospheric measurements, Aerosol Sci. Technol., 39, 206-221, https://doi.org/10.1080/027868290913988, 2005.

Robinson, T.-B., Stolle, C., and Wurl, O.: Depth is relative: the importance of depth for transparent exopolymer particles in the near-surface environment, Ocean Sci., 15, 1653-1666, https://doi.org/10.5194/os-15-1653-2019, 2019a.

Robinson, T.-B., Wurl, O., Bahlmann, E., Jürgens, K., and Stolle, C.: Rising bubbles enhance the gelatinous nature of the air-sea interface, Limnol. Oceanogr., 64, 2358-2372, https://doi.org/10.1002/lno.11188, 2019b.

Salter, M. E., Zieger, P., Navarro, J. C. A., Grythe, H., Kirkevag, A., Rosati, B., Riipinen, I., and Nilsson, E. D.: An empirically derived inorganic sea spray source function incorporating sea surface temperature, Atmos. Chem. Phys., 15, 11047-11066, https://doi.org/10.5194/acp-15-11047-2015, 2015.
Schepanski, K., Tegen, I., and Macke, A.: Saharan dust transport and deposition towards the tropical northern Atlantic, Atmos. Chem. Phys., 9, 1173-1189, https://doi.org/10.5194/acp-9-11732009, 2009.

Schmetz, J., Pili, P., Tjemkes, S., Just, D., Kerkmann, J., Rota, S., and Ratier, A.: An introduction to Meteosat Second Generation (MSG), Bull. Am. Meteorol. Soc., 83, 977-992, https://doi.org/10.1175/BAMS-83-7-Schmetz-1, 2002.

Simoneit, B. R. T., Chester, R., and Eglinton, G.: Biogenic lipids in particulates from lower atmosphere over eastern Atlantic, Nature, 267, 682-685, 1977.

Simoneit, B. R. T., Kobayashi, M., Mochida, M., Kawamura, K., Lee, M., Lim, H. J., Turpin, B. J., and Komazaki, Y.: Composition and major sources of organic compounds of aerosol particulate matter sampled during the ACE-Asia campaign, J. Geophys. Res.-Atmos., 109, D19S10, https://doi.org/10.1029/2004JD004598, 2004.

Stolle, C., Nagel, K., Labrenz, M., and Jürgens, K.: Succession of the sea-surface microlayer in the coastal Baltic Sea under natural and experimentally induced low-wind conditions, Biogeosciences, 7, 2975-2988, https://doi.org/10.5194/bg-7-29752010, 2010.

Stolle, C., Ribas-Ribas, M., Badewien, T. H., Barnes, J., Carpenter, L. J., Chance, R., Damgaard, L. R., Durán Quesada, A. M., Engel, A., Frka, S., Galgani, L., Gašparović, B., Gerriets, M., Hamizah Mustaffa, N. I., Herrmann, H, Kallajoki, L., Pereira, R., Radach, F., Revsbech, N. P., Rickard, P., Saint, A., Salter, M., Striebel, M., Triesch, N., Uher, G., Upstill-Goddard, R. C., van Pinxteren, M., Zäncker, B., Zieger, P., and Wurl, O.: The MILAN campaign: Studying diel light effects on the air-sea interface, Bull. Am. Meteorol. Soc., 101, E146-E166, https://doi.org/10.1175/BAMS-D-17-0329.1, 2019.

Stramma, L., Huttl, S., and Schafstall, J.: Water masses and currents in the upper tropical northeast Atlantic off northwest Africa, J. Geophys. Res.-Ocean., 110, C12006, https://doi.org/10.1029/2005jc002939, 2005.

Tang, K., Page, J. S., and Smith, R. D.: Charge competition and the linear dynamic range of detection in electrospray ionization mass spectrometry, J. Am. Soc. Mass Spectr., 15, 1416-1423, https://doi.org/10.1016/j.jasms.2004.04.034, 2004.

Triesch, N., van Pinxteren, M., Engel, A., and Herrmann, H.: Concerted measurements of free amino acids at the Cape Verde Islands: High enrichments in submicron sea spray aerosol particles and cloud droplets, Atmos. Chem. Phys. Discuss., https://doi.org/10.5194/acp-2019-976, in review, 2020.

van Pinxteren, D., Brueggemann, E., Gnauk, T., Mueller, K., Thiel, C., and Herrmann, H.: A GIS based approach to back trajectory analysis for the source apportionment of aerosol constituents and its first application, J. Atmos. Chem., 67, 1-28, https://doi.org/10.1007/s10874-011-9199-9, 2010.

van Pinxteren, M.: Concentrations of pigments, DOC and microbial parameters in the Sea surface Microlayer (SML) and bulk water during MarParCloud at Cape Verde islands, LeibnizInstitut für Troposphärenforschung e.V., Leipzig, PANGAEA, https://doi.org/10.1594/PANGAEA.910693, 2020a.

van Pinxteren, M.: Seawater chemistry during MarParCloud at Cape Verde islands. Leibniz-Institut für Troposphärenforschung e.V., Leipzig, PANGAEA, https://doi.org/10.1594/PANGAEA.910692, 2020b, 
van Pinxteren, M. and Herrmann, H.: Glyoxal and methylglyoxal in Atlantic seawater and marine aerosol particles: method development and first application during the Polarstern cruise ANT XXVII/4, Atmos. Chem. Phys., 13, 11791-11802, https://doi.org/10.5194/acp-13-11791-2013, 2013.

van Pinxteren, M., Müller, C., Iinuma, Y., Stolle, C., and Herrmann, H.: Chemical Characterization of Dissolved Organic Compounds from Coastal Sea Surface Micro layers (Baltic Sea, Germany), Environ. Sci. Technol., 46, 10455-10462, https://doi.org/10.1021/es204492b, 2012.

van Pinxteren, M., Fiedler, B., van Pinxteren, D., Iinuma, Y., Koertzinger, A., and Herrmann, H.: Chemical characterization of sub-micrometer aerosol particles in the tropical Atlantic Ocean: marine and biomass burning influences, J. Atmos. Chem., 72, 105-125, 2015.

van Pinxteren, M., Barthel, S., Fomba, K., Müller, K., von Tümpling, W., and Herrmann, H.: The influence of environmental drivers on the enrichment of organic carbon in the sea surface microlayer and in submicron aerosol particles - measurements from the Atlantic Ocean, Elem. Sci. Anth., 5, 35, https://doi.org/10.1525/elementa.225, 2017.

Vaughan, S., Ingham, T., Whalley, L. K., Stone, D., Evans, M. J., Read, K. A., Lee, J. D., Moller, S. J., Carpenter, L. J., Lewis, A. C., Fleming, Z. L., and Heard, D. E.: Seasonal observations of $\mathrm{OH}$ and $\mathrm{HO}_{2}$ in the remote tropical marine boundary layer, Atmos. Chem. Phys., 12, 2149-2172, 10.5194/acp-12-2149-2012, 2012.

Watne, Å. K., Psichoudaki, M., Ljungström, E., Le Breton, M., Hallquist, M., Jerksjö, M., Fallgren, H., Jutterström, S., and Hallquist, А. M.: Fresh and Oxidized Emissions from In-Use Transit Buses Running on Diesel, Biodiesel, and CNG, Environ. Sci. Technol., 52, 7720-7728, https://doi.org/10.1021/acs.est.8b01394, 2018.

Wex, H., Dieckmann, K., Roberts, G. C., Conrath, T., Izaguirre, M. A., Hartmann, S., Herenz, P., Schäfer, M., Ditas, F., Schmeissner, T., Henning, S., Wehner, B., Siebert, H., and Stratmann, F.: Aerosol arriving on the Caribbean island of Barbados: physical properties and origin, Atmos. Chem. Phys., 16, 14107-14130, https://doi.org/10.5194/acp-16-14107-2016, 2016.

Wiedensohler, A., Birmili, W., Nowak, A., Sonntag, A., Weinhold, K., Merkel, M., Wehner, B., Tuch, T., Pfeifer, S., Fiebig, M., Fjaraa, A. M., Asmi, E., Sellegri, K., Depuy, R., Venzac, H., Villani, P., Laj, P., Aalto, P., Ogren, J. A., Swietlicki, E., Williams, P., Roldin, P., Quincey, P., Huglin, C., Fierz-Schmidhauser, R., Gysel, M., Weingartner, E., Riccobono, F., Santos, S., Gruning, C., Faloon, K., Beddows, D., Harrison, R. M., Monahan, C., Jennings, S. G., O’Dowd, C. D., Marinoni, A., Horn, H. G., Keck, L., Jiang, J., Scheckman, J., McMurry, P. H., Deng, Z., Zhao, C. S., Moerman, M., Henzing, B., de Leeuw, G., Loschau, G., and Bastian, S.: Mobility particle size spectrometers: harmonization of technical standards and data structure to facilitate high quality long-term observations of atmospheric particle number size distributions, Atmos. Meas. Tech., 5, 657-685, https://doi.org/10.5194/amt-5-657-2012, 2012.
Wolke, R., Knoth, O., Hellmuth, O., Schröder, W., and Renner, E.: The parallel model system LM-MUSCAT for chemistrytransport simulations: Coupling scheme, parallelization and application, in: Parallel Computing: Software Technology, Algorithms, Architectures, and Applications, edited by: Joubert, G. R., Nagel, W. E., Peters, F. J., and Walter, W. V., Elsevier, Amsterdam, Niederlande, 363-370, 2004.

Wurl, O., Miller, L., Ruttgers, R., and Vagle, S.: The distribution and fate of surface-active substances in the seasurface microlayer and water column, Mar. Chem., 115, 1-9, https://doi.org/10.1016/j.marchem.2009.04.007, 2009.

Wurl, O., Wurl, E., Miller, L., Johnson, K., and Vagle, S.: Formation and global distribution of sea-surface microlayers, Biogeosciences, 8, 121-135, https://doi.org/10.5194/bg-8-1212011, 2011.

Wurl, O., Stolle, C., Van Thuoc, C., The Thu, P., and Mari, X.: Biofilm-like properties of the sea surface and predicted effects on air-sea $\mathrm{CO}_{2}$ exchange, Prog. Oceanogr., 144, 15-24, https://doi.org/10.1016/j.pocean.2016.03.002, 2016.

Wurl, O., Ekau, W., Landing, W. M., and Zappa, C. J.: Sea surface microlayer in a changing ocean - A perspective, Elementa-Science of the Anthropocene, 5, 31, https://doi.org/10.1525/elementa.228, 2017.

Zabalegui, N., Manzi, M., Depoorter, A., Hayeck, N., Roveretto, M., Li, C., van Pinxteren, M., Herrmann, H., George, C., and Monge, M. E.: Seawater Analysis by Ambient Mass Spectrometry-Based Seaomics and Implications on Secondary Organic Aerosol Formation, Atmos. Chem. Phys. Discuss., https://doi.org/10.5194/acp-2019-852, in review, 2019.

Zäncker, B., Cunliffe, M., and Engel, A.: Bacterial Community Composition in the Sea Surface Microlayer Off the Peruvian Coast, Front. Microbiol., 9, 2699, https://doi.org/10.3389/fmicb.2018.02699, 2018.

Zindler, C., Peeken, I., Marandino, C. A., and Bange, H. W.: Environmental control on the variability of DMS and DMSP in the Mauritanian upwelling region, Biogeosciences, 9, 1041-1051, https://doi.org/10.5194/bg-9-1041-2012, 2012. 